\title{
Cyber-Physical Systems as an Enabler of Circular Economy to Achieve Sustainable Development Goals: A Comprehensive Review
}

\author{
Aser Alaa Ahmed ${ }^{1} \cdot$ Mohammad A. Nazzal $^{1,2}\left(\right.$ Basil M. Darras $^{1}$ \\ Received: 10 May 2021 / Revised: 18 September 2021 / Accepted: 3 October 2021 / Published online: 29 October 2021 \\ (c) Korean Society for Precision Engineering 2021
}

\begin{abstract}
Industrialization has brought wealth, prosperity, and abundance to many nations. However, it has had many drawbacks on people's health and the environment. Several paradigms have been proposed and implemented in an effort to suppress and reverse the adverse impacts of human activities and industrialization. A popular approach that serves as a solution to many of the negative implications of industry today is the circular economy (CE). With today's top-notch technologies, the transition from the conventional linear economy to $\mathrm{CE}$ has been made easier. For example, the implementation of cyber-physical systems (CPSs), an Industry 4.0 (I4.0) tool, within a CE can substantially increase efficiency and reduce waste. This work presents a thorough review on the applications of cyber-physical systems within each of the CE stages, the contribution of different CPS technologies to the sustainable development goals (SDGs), and the current state of the CE assessment tools. The contribution of different CPS tools to each CE stage is demonstrated through several practical examples. In addition, this work reveals how the different CPS technologies applications contribute to the attainment of different SDGs set by the United Nations. It is also deduced from the review of the current state of the CE assessment tools that there is a need for a standardized comprehensive CE measuring or rating system to allow businesses on the micro, meso, and macro levels of the economy improve their circulatory.
\end{abstract}

Keywords Circular economy · Cyber-physical systems $\cdot$ Sustainable development goals $\cdot$ Industry $4.0 \cdot$ Sustainability . Circular economy assessment

\section{Introduction}

The world's population has drastically increased over the course of the past few decades. It is estimated that the population will reach 8.5 billion by 2030 and 10.9 billion by 2100 [1]. Subsequently, this fast-paced population growth contributes to a substantial increase in energy demand and consumption. Energy consumption is projected to increase by $50 \%$, reaching approximately 900 quadrillion British thermal units (Btu) by 2050 as seen in Fig. 1 [2].

Human activities have caused an estimated $1.0^{\circ} \mathrm{C}$ of global warming above pre-industrial levels [3]. The concentration of $\mathrm{CO}_{2}$ in the atmosphere has been increasing

Mohammad A. Nazzal

mnazzal@aus.edu

1 Mechanical Engineering Department, American University of Sharjah, Sharjah, UAE

2 Mechanical Engineering Department, German Jordanian University, Madaba, Jordan since industrialization. Countries such as China, India and the USA attract most of the global industries, which explains the huge amount of $\mathrm{CO}_{2}$ produced by these nations as seen in Fig. 2 [4]. This slight increase in the Earth's temperature has melted ice caps causing extreme weather conditions and changed rainfall patterns across the globe.

In general, energy used in the industrial sector was responsible for about $24.4 \%$ of the global greenhouse gas emissions (GHG) in 2016. It is followed by transportation accounting for $16.2 \%$ [5]. Global warming can cause floods in some places and extreme drought in other places. It threatens marine life and biodiversity, leads to deterioration of food security situations, and causes population displacement [6].

Another problem associated with industrialization and human activities is waste generation. In 2018, the USA landfilled about 146.2 million tons of municipal solid waste (MSW). Food waste accounted for the largest portion with about $24 \%$ of the total waste followed by plastics, paper, and paperboard [7]. 
Fig. 1 Global primary energy consumption by world region in $2019[2]$

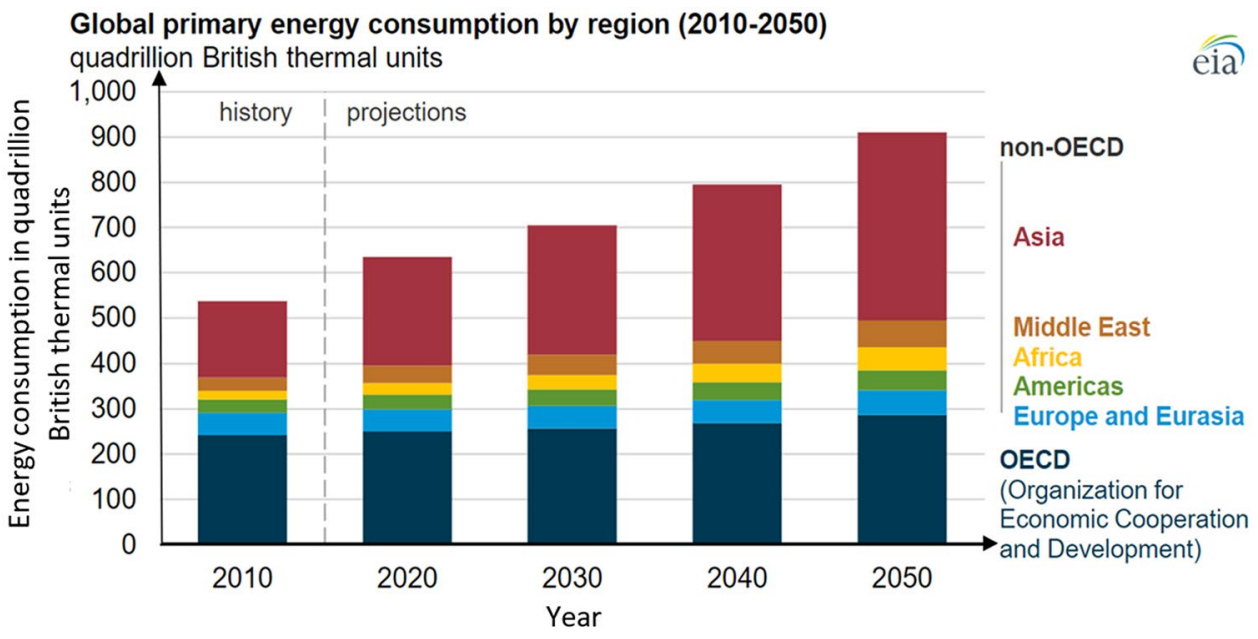

\section{Annual $\mathrm{CO}_{2}$ emissions, 2018}

Carbon dioxide $\left(\mathrm{CO}_{2}\right)$ emissions from the burning of fossil fuels for energy and content

production. Land use change is not included.

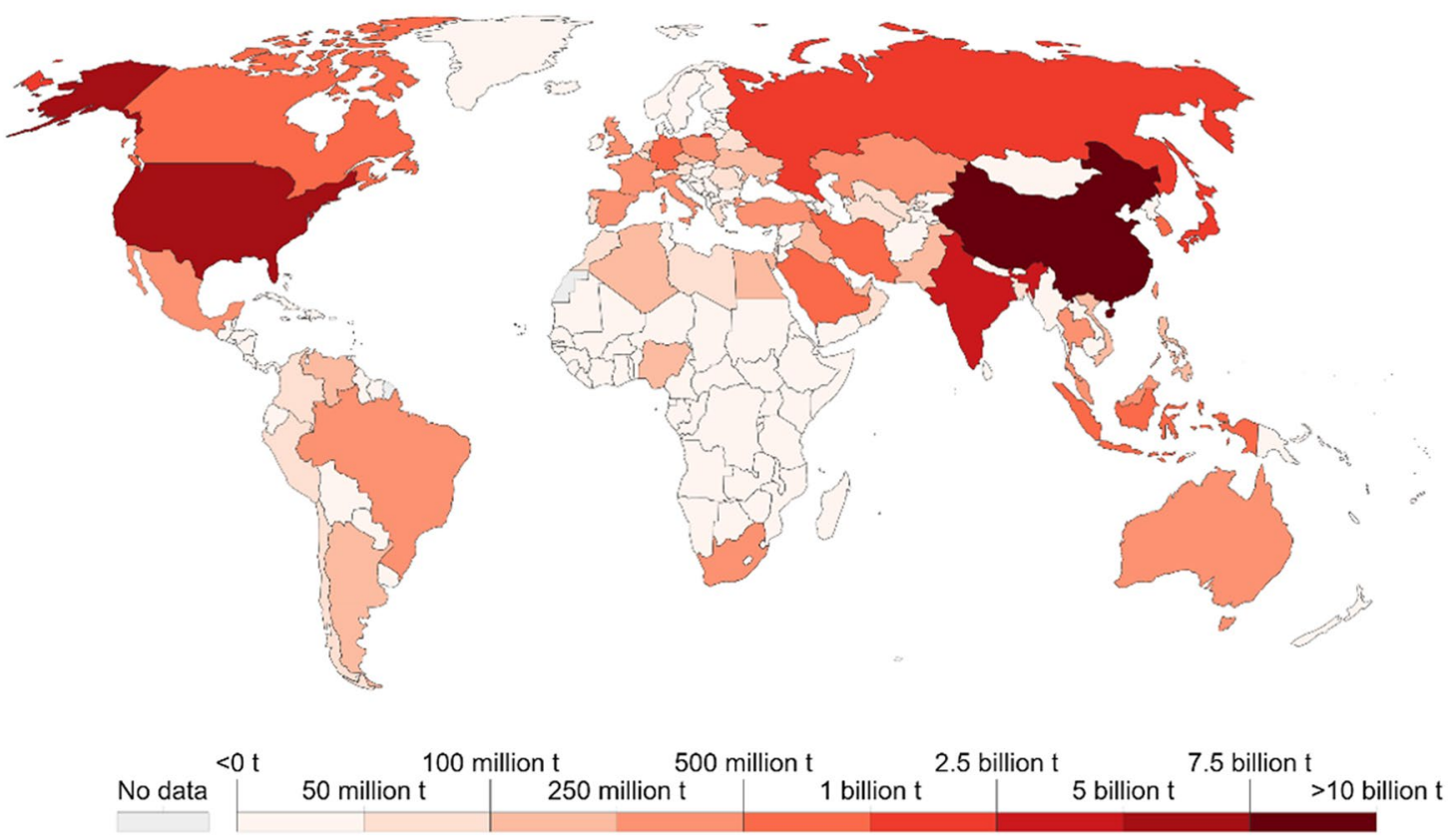

Source: Global Carbon Project; Carbon Dioxide Information Analysis Centre (CDIAC)

Note: $\mathrm{CO}_{2}$ emissions are measured on a production basis, meaning they do not correct for emissions embedded in traded goods. OurWorldInData.org/co2-and-other-greenhouse-gas-emissions

Fig. 2 Annual $\mathrm{CO}_{2}$ emissions in 2018 by country [4]

One of the most prominent strategies to limit and reverse the severe effects of climate change and the impacts of waste accumulation is the adoption of a circular economy (CE). In the traditional "one-way" or in other words, "linear" manufacturing model, raw materials are used to manufacture goods that are sold, used, and then discarded as waste to landfills [8]. In contrast, the CE model is a waste conservative model that is defined as "An Industrial system that is restorative or regenerative by intention and design" [9]. CE focuses on achieving prosperous economic development while protecting the environment by saving resources through recycling. It also takes social aspects 
into consideration [10,11]. Similarly, the United Nations defined sustainable development (SD) as "meeting the needs of the present without compromising the ability of future generations to meet their own needs" [12]. In 2002, economic development, social development and environmental protection were defined during the World Summit on SD as the three main sustainability pillars [13]. Since both CE and SD share the same goals, CE could be defined as a condition for SD in general [14-16]. Studies suggest that the transition to $\mathrm{CE}$ and its implementation in the manufacturing industry would contribute to the making of new business opportunities as well as representing a new sustainable growth path [11]. Consequently, CE practices can potentially save around $80-90 \%$ of raw materials and energy consumption when compared to the linear model [17]. Economically speaking, CE practices can potentially cut product costs by $25-30 \%$ [17]. An optimistic study revealed that the implementation of CE practices in Europe could have an annual benefit of around 1.8 trillion Euros by 2030 [18]. Correspondingly, the rise in the demand of sustainable products driven by the reduced prices would create more job opportunities in the sustainable sector [19]. These promising figures have caused many countries, such as China, Japan, Canada, the United States and Brazil, to aim at attaining sustainable development goals (SDGs) by implementing CE across their different industries and sectors [20].

A general CE model is presented in Fig. 3. CE can be divided into five stages with design and transportation being a common interconnecting stage among all the individual stages. The five stages are: sourcing, manufacturing, distribution, use, and recovery. However, this paper will include design as a stage which is in place prior to manufacturing. Each stage plays an important role in keeping the model circular; "leakages" in any of the stages cause a discontinuity, defeating the purpose of the circular paradigm. Over the past few years, the implementation of the $\mathrm{CE}$ paradigm throughout industries has led to the emergence of new supporting technologies that have eased the adoption of sustainable manufacturing measures into the $\mathrm{CE}$ cycle. This type of manufacturing is known as circular manufacturing (CM) [16].

Similarly, different stages in the economy need to undergo technological updates to ease their transformation from a linear economy to a CE. There has always been a need to develop all outdated technologies into smart ones. Machines are now required to understand and interpret the physical world and to perform tasks flawlessly for better service. For that to happen, there should be a system that would
Fig. 3 A general circular economy (CE) model [21]

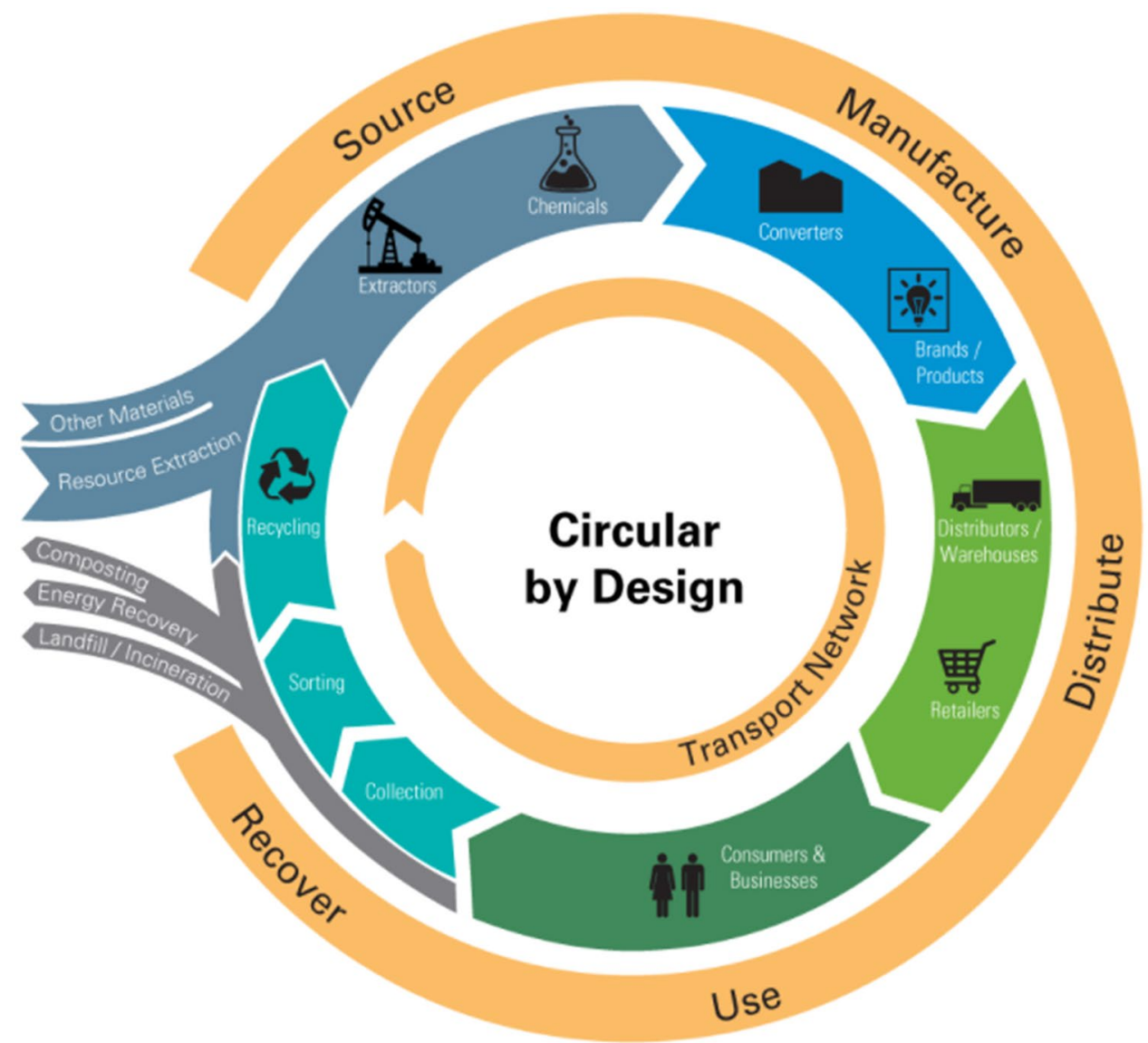


obtain information from the physical world and translate it in a way that can be understood by machines in their cyber world. Fortunately, these types of systems exist and are called cyber-physical systems (CPSs). In general, Industry 4.0 (I4.0) tools, such as CPSs, the internet of things (IoT), augmented reality, big data, simulation, autonomous robots, cloud computing, additive manufacturing, cyber-security, and artificial intelligence can be key enablers for CE. Several papers joined more than one I4.0 tools together to increase the capabilities of different processes. For example, dyeing processes were updated to save energy using different I4.0 tools [22]. Another paper reviewed smart machining processes using machine learning [23].

The shared goals of the confluence and integration of CE and I4.0 can be illustrated using the House of Sustainability shown in Fig. 4. People are considered the foundation of the sustainability house, while the purpose is what drives people towards their goals. The incorporation of different I4.0 tools within the CE builds a strong support that different SDGs can lean on. These goals are the building blocks of sustainable development (SD). Together, they achieve different attributes of the three pillars of SD: environmental, economic, and social. The House of Sustainability provides a clear picture of how I4.0 and CE complement each other. Without the supporting I4.0 tools, CE is not sufficient to achieve SD. Similarly, incorporating I4.0 tools into a linear economy will not achieve SD.

Several papers review the implementation of I4.0 tools in the CE. Very few however link the integration of I4.0 technological tools into the CE to the achievement of SDGs. Almost none present a comprehensive review in terms of the CE stages while linking them to the possible SDGs achieved. Table 1 presents different review papers that directly mentions the implementation of different I4.0 tools into the CE. The table presents the I4.0 tools mentioned in the review papers, the CE stages targeted, and the SDGs achieved if any.

Firstly, Kerin and Pham [24] reviewed the literature on the emerging digital technologies of I4.0 in remanufacturing. As a conclusion, it was found that such an implementation of I4.0 technologies, mainly IoT, VR and AR, contribute to the achievement of goals 9.4 and 12.5 of

Fig. 4 House of sustainability

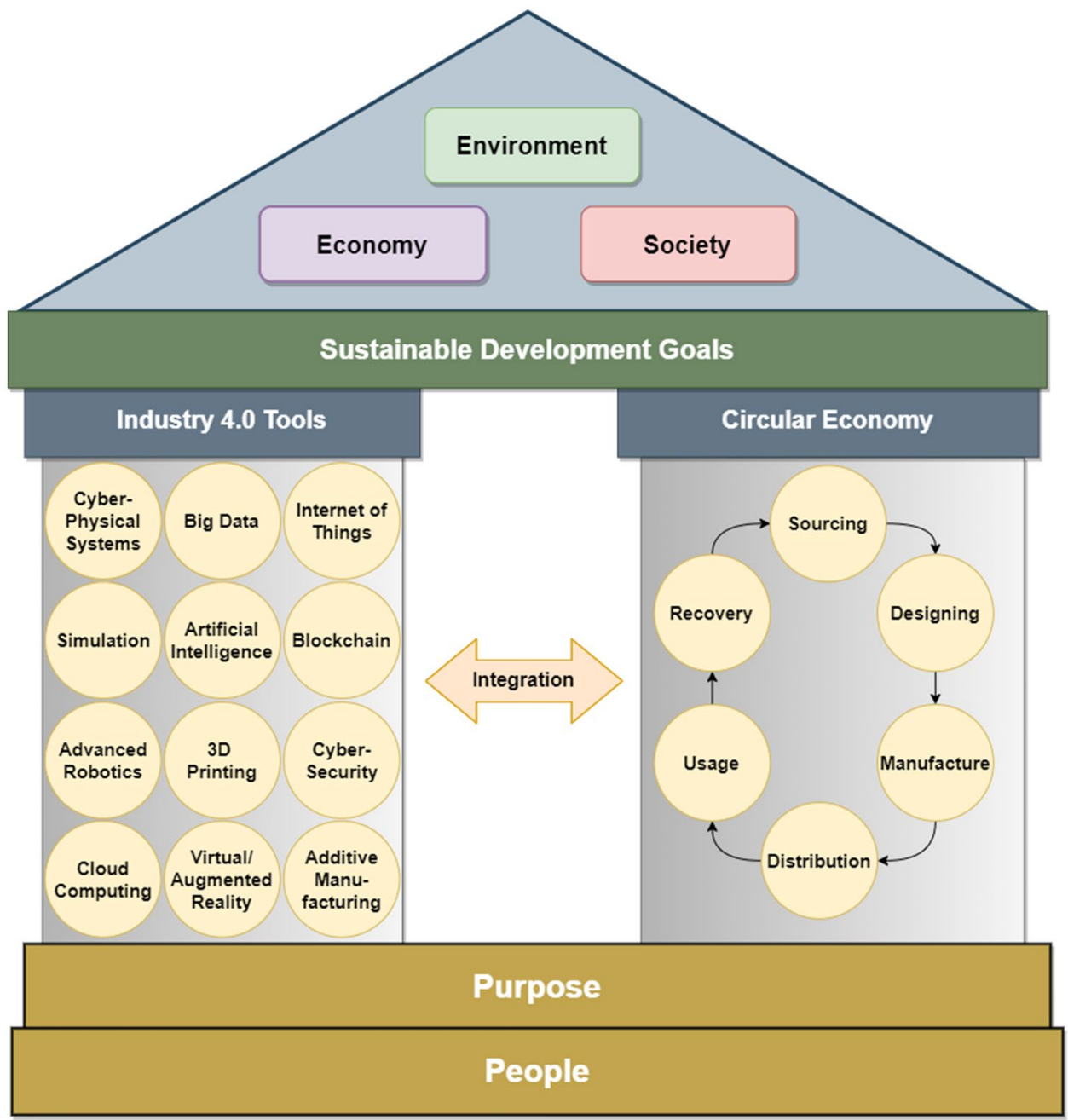


Table 1 List of review papers on the implementation of I4.0 in CE

\begin{tabular}{llll}
\hline Source & Industry 4.0 Tool & CE Stage & SDGs \\
\hline Kerin and Pham (2019) [24] & AI, AM, AR, VR, IoT & Manufacturing & $9.4,12.5$ \\
Sarc et al. (2019) [25] & IoT, CPSs, Blockchain, AI & Recycling (Waste Management) & Not Included \\
Dantas et al. (2021) [26] & AM, AI, Blockchain, IoT, & CE Practices in: & 7, 8, 9, 11, 12, 13 \\
& Simulation, CPSs, Cybersecu- & Design, Manufacturing, Distribution, Recycling \\
& rity, AR & & Not Included \\
Gupta et al. (2021) [27] & IoT, Bigdata, Smart factory, & Manufacturing, Usage, Recycling & Not Included \\
Leng et al. (2020) [25] & Cloud computing, AM, CPSs & & Not Included \\
Khan et al. (2021) [28] & Blockchain & Manufacturing & CE implementations: \\
& I4.0-based technologies & Smart cities/factories, supply chains & \\
\hline
\end{tabular}

the SDGs. A similar approach was illustrated by Dantas et al. [26] in a paper that presented a review on how the combination of $\mathrm{CE}$ and I4.0 contributes towards achieving different SDGs. The authors reviewed papers in terms of $\mathrm{CE}$ practices and not CE stages. As a result, some stages were missed such as the sourcing and the usage stages. Out of the 50 papers reviewed, 42 directly addressed a CE practice, and 17 out of these 42 papers discussed an I4.0 tool. Generally, the authors did not capture all CE stages due to the nature of the review that focuses on CE practices rather than CE stages individually. On the other hand, Gupta et al. [27] presented a range of I4.0 technologies implemented on $3 \mathrm{CE}$ stages which are the manufacturing, usage, and recycling stages. However, SDGs were not covered in the review. Moreover, Leng et al. [29] reviewed different aspects of the manufacturing stage focusing on blockchain technologies individually, with no reference to the SDGs achieved. Sarc et al. [25] also reviewed the implementation of various I4.0 technologies in waste management but without including SDGs in the review. Another review by Khan et al. [28] mapped I4.0 to CE and sustainable business model perspectives. However, CE was discussed from the implementation perspective and not from stages point of view. Also, SDGs were not discussed in this review. Overall, it can be clearly noticed that reviews focusing on the implementation of I4.0 tools in the CE fail to capture either all CE stages or does not incorporate SDGs. Due to the vast amount of I4.0 present, it is very hard to capture how the implementation of these technologies in different CE stages achieve different SDGs. Hence, to present a novel review on the topic, this paper reviews possible ways the integration of one I4.0 tool, the cyber-physical systems (CPSs), into each of the CE stages facilitates the achievement of different SDGs. Also, it highlights the need of a comprehensive CE assessment tool, and reviews some of the tools presented in the field and literature.

\section{Cyber-Physical Systems}

As Fig. 5 illustrates, CPSs can be defined as systems that "consist of computation, communication and control components tightly combined with physical processes of different domains such as mechanical, electrical, and chemical" [30]. CPSs enhance the potential of physical systems by interacting with physical processes using deeply embedded computations and communications that control and monitor physical processes through feedback loops. This allows physical processes to affect computations and vice versa [31]. In other words, CPSs provide a real time linkage between humans and physical or production systems. This linkage is created using sensors, actuators, and computers through a network [32].

There are six main components needed to fully develop CPSs. These components are sensors and actuators that are used to interact with the physical world; a power supply, as

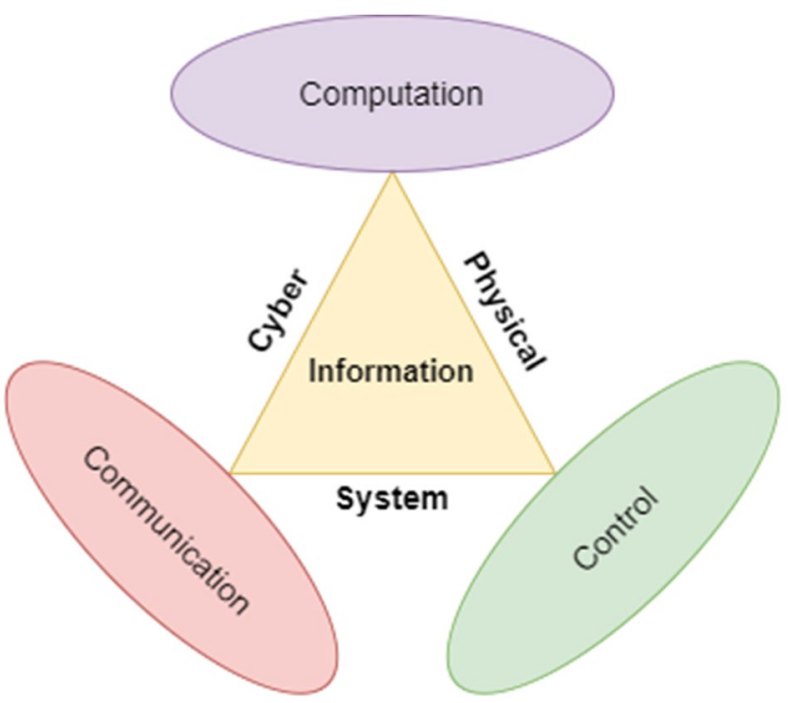

Fig. 5 Cyber-physical system (CPS) components [33] 
well as analog and digital hardware components, such as power electronics and digital convertors, respectively, a network; and lastly, the heterogeneous software microprocessors or microcontrollers that are used for software execution. Due to their flexibility, CPS technologies define the newest ongoing industrial revolution by their enormous application domains. Such applications include but are not limited to communications, consumer services, energy, infrastructure, healthcare, manufacturing, robotics, military, and transportation.

Throughout the literature, authors often discuss IoT and CPSs as interchangeable concepts. This is due to the overlap between these two concepts. IoT is when the "virtual world of information technology integrates seamlessly with the real world of things" [34]. Moreover, IoT involves three main steps that occur iteratively in the following order: sensing, thinking, and acting [35]. The aforementioned points apply to CPSs as well. However, the major difference between these two concepts is the use of the internet. The IoT relies on the internet to link between the virtual and the physical worlds. In contrast, CPSs can use either the internet or a feedback loop. Hence, it is safe to say that IoT is a special class of CPS that only uses the internet. However, since this is debatable, this paper will focus mainly on CPSs using feedback loops with only some examples requiring a minimum use of the internet.

The CE paradigm is presented as a solution to tackle previously mentioned drawbacks of human activities in general and industrialization in particular. Moreover, I4.0 describes an innovative manufacturing path that transforms conventional manufacturing to a more sustainable and conservative model by utilizing different technological tools. Both concepts were coined separately on different occasions but due to their shared goals, many papers [36-41] have connected I4.0 to CE. As of yet, no one has established a comprehensive connection among and between all CE stages with a specific I4.0 tool. Instead, they have focused on only one stage, mainly manufacturing or logistics, while keeping the rest of the CE model unchanged. In contrast to the conventional CE model, which does not include I4.0 tools, this paper presents an up-to-date version of the $\mathrm{CE}$ paradigm that exhibits how sustainability can be achieved across different CE stages by implementing one of the most important I4.0 enablers, CPSs. This is presented by highlighting how CPSs impact each stage of the CE. In addition, the relevant SDGs that are achieved through the CPS enabled CE are revealed and discussed.

\section{Intra-Impact}

This section discusses how CPSs can be embedded into each stage of the CE model. This highlights the potential of CPSs for enhancing each stage of the CE in terms of efficiency and sustainability.

\subsection{Sourcing}

Sourcing is the first stage of the CE. Most of the raw materials needed by manufacturers are obtained through the use of different extraction processes in the sourcing stage. The main challenges faced in this stage are the excessive exhaustion of raw materials, the environmental impact, as well as the health risks involved in the extraction process. The implementation of different I4.0 enablers, such as IoT and big data, play an important role when it comes to the optimization of resources and decision-making processes. However, this section will present how CPSs alone could impact resource mining.

\subsubsection{Autonomous Mining Operations}

CPSs can be harnessed to tackle health risks posed during mining and other methods of extracting resources. For example, toxic levels of arsenic present in gold mining areas in the Amazon pose health risks to miners and locals [42]. To reduce human exposure to arsenic, CPSs could be implemented to automate some of the mining tasks. In his paper, Wang et al. [43] presented the Human-Robot collaborative assembly. This system was originally proposed for manufacturing facilities. With minor modifications, the HumanRobots assembly can be employed and directed throughout dangerous mining processes, thus creating a safer working environment, and reducing the hazards that the miners are exposed to. It also provides an equal opportunity for laborers since physical work would be minimal as the operation of such robots is relatively easy.

\subsection{Design}

Constant design improvements and a tailored customer experience are the new focus of many industries [44]. For these reasons, it was essential to allocate I4.0 tools in the design of products. CPSs can be used extensively to aid designers by providing them with data that can be used in predicting their design performances or by presenting different designs using previous knowledge.

\subsubsection{Design Information Feedback System}

One of the most promising of the proposed approaches for the enhancement of product designs is through "the information feedback, provided through CPSs within production facilities" [45]. In this approach, data gathered in the production phase is transformed into usable knowledge for design improvement. Figure 6 presents an approach which begins with sensors and ends with design rules. To explain further, the authors' approach is to use CPS sensors to gather data which is then classified so that weaknesses or failures 
within the process can be identified. Hence, CPSs can provide information about irregularities in the process as well as distinct failure states. Through the use of a knowledge base that contains an existing correlation between failure and cause, a reported failure state and its root causes can be deduced. The cause is then assigned to the feature responsible for the cause through another knowledge base. Created by engineers and designers, the last knowledge base provides information on how to avoid detected failures throughout the process of production.

\subsubsection{Testing and Simulation Assistance in Product Design}

It is important for designers to be able to test their designs before they are produced. For this reason, it is necessary to develop testing and simulation equipment and procedures that accomplish this task in the safest, cheapest, and most timely fashion. Well-known aircraft testing platforms were made possible by CPSs. One of these platforms is the wind-tunnel, which is a widely employed technique used for testing full or scale model components and guides detailed design decisions in thermal-fluid systems [47]. There are various types of wind tunnels, each equipped with a different set of sensors for obtaining data. For example, climate tunnels, which are used to simulate different environmental conditions, are equipped with different sensors than those of smoke tunnels, which are used for flow visualization. Stability tunnels, which are used to study flight dynamics, require different sensors than icing tunnels, which study the effects of ice formation on aircraft wings [47]. A knowledge of the forces exerted on aircraft bodies is critical to aerospace designs; hence, piezoelectric sensors are attached to the aircraft body to measure the dynamic and the quasi-static forces exerted on the aircraft body at different locations. Moreover, acoustic pressure microphones are used to measure dynamic and acoustic pressure in aircraft and rocket applications [48]. These sensors, along with cameras, angle encoders, motors and other components are illustrated in Fig. 7. They equip designers with valuable and critical data without the need to implement a test on the actual aircraft; instead, a scaled model is used. This cuts down the costs and eliminates different hazards caused by design failures.

\subsubsection{Design for Manufacturing and Assembly}

Design for manufacturing and assembly (DFMA) is a method of designing products that aims to ease the manufacturability and assembly of the components of the product. The main aim of DFMS is to reduce the materials used and the labor costs, which in return reduces the overall costs of the product assembly and the production. CPSs can assist with the decisions made by the designers. As seen in Fig. 8, the manufacturing for assembly (MFA) procedure is carried out in five main steps. Firstly, designers work on reducing the number of parts required for the initial design. Secondly, the required or practical parts are determined and counted. Afterwards, the overall product quality is determined based on the product requirements. In the next step, the designers determine the proper assembly methods. Lastly, the design is finalized and executed for production. During the aforementioned process, many decisions are made by the designers. These decisions are based on specific criteria, constraints, material properties, and other considerations. This process would require lots of planning time, and would result in human errors, production costs for any faulty designs, and the operating time for the machines. To avoid this, an

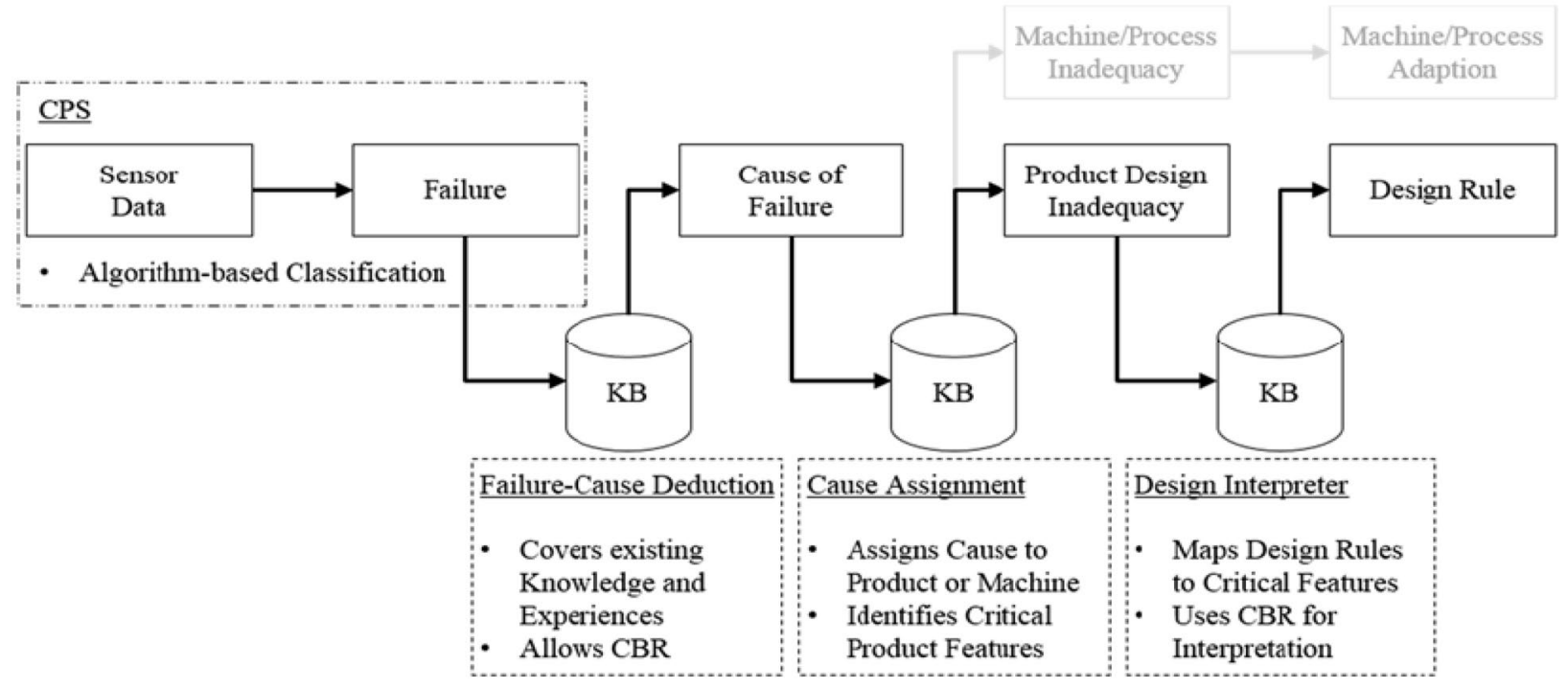

Fig. 6 Knowledge feedback to a design process via CPS [46] 
Fig. 7 Wind tunnel equipped with cameras and sensors representing a CPS

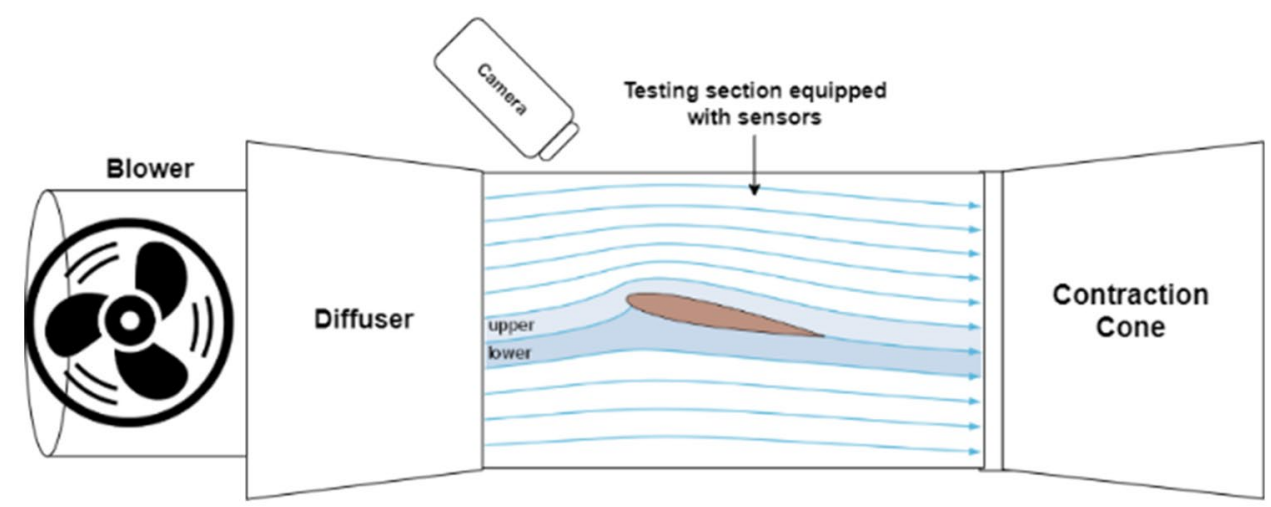

Knowledge

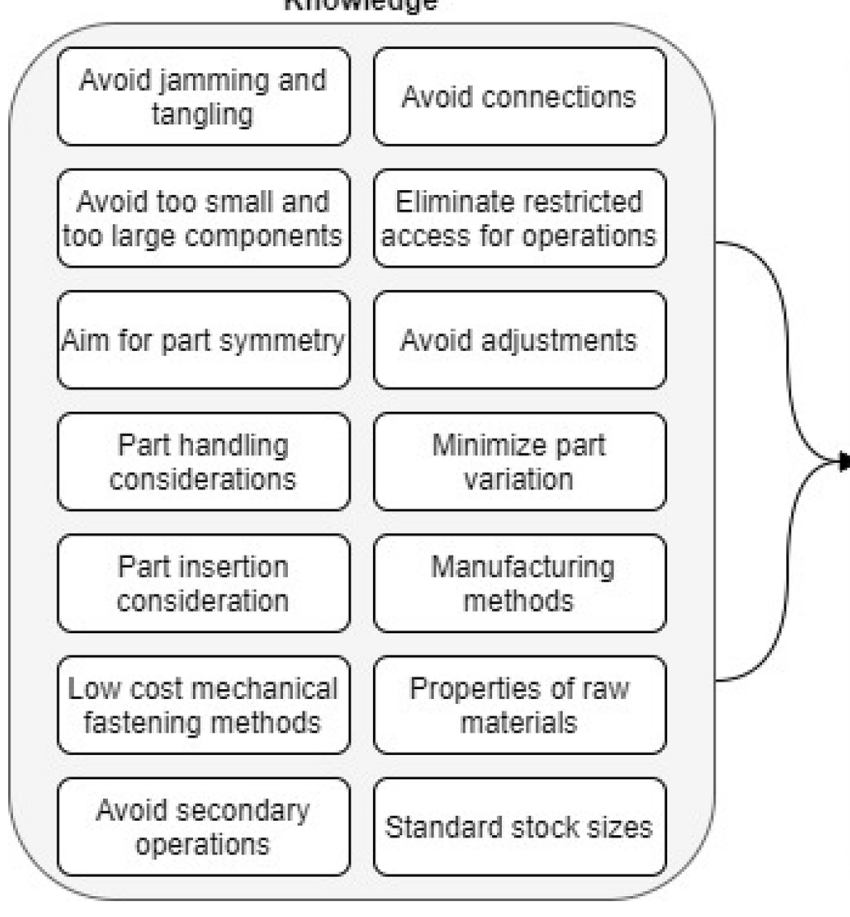

Role of CPSs

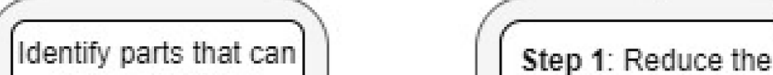

be standardized

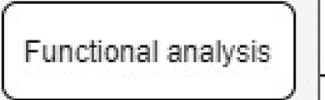
number of unique parts

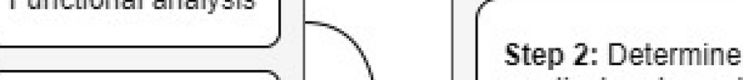
practical part count

Identify quality opportunities

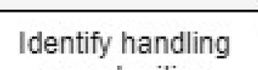
opportunities

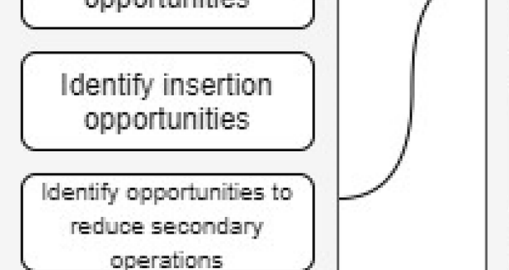

Step 4: Determine assembly methods

\section{Analyze data for new design}

Step 5: Finalize product design

Fig. 8 Design for manufacturing and assembling the CPS

architecture similar to the "design information feedback system" could be utilized, in which data presented in the "Knowledge" section of Fig. 8 is interpreted by CPSs consisting of software applications, embedded sensors, and feedback loops. The CPSs then make a series of decisions, which include the following: identifying parts that can be standardized; identifying quality opportunities where quality could be compromised if possible; identifying handling opportunities based on the availability of machines and assembly lines; identifying insertion opportunities; identifying opportunities to reduce secondary operations, such as welding; and finally, analyzing data to present the new design. These decisions are then presented to the designers for a final decision. As a result, manufacturers save substantially on costs that were previously spent on product design $[49,50]$.

\subsection{Manufacturing}

Manufacturing is an integral part of CPSs; for example, the integration of CPSs in manufacturing produces cyber-physical production systems (CPPSs). These systems combine the advancements in communication and information technologies as well as those in computer science with advances in manufacturing science technology and the integration of production logistics [30]. In other words, "CPPSs consist of autonomous and cooperative elements and sub-systems that are connected based on the context within and across 
all levels of production, from processes through machines up to production and logistics networks" [51]. The use of CPSs could solve many critical challenges in manufacturing, such as quality control, defect prediction, energy consumption, machine health monitoring, and the increasing need for direct human-machine collaboration and most importantly the making of smart factories [52-54].

\subsubsection{Quality Control and Quality Assurance}

Quality control (QC) and quality assurance (QA) are procedures carried out by manufacturers on their products and processes respectively to ensure adherence to standards and quality criteria, and to meet the requirements of customers and clients. Internally, manufacturers should assess the quality of their product after each stage preventing defective products from passing into the next stage. Lee et al. [55] proposed an "architecture framework to implement the CPPSs cooperating with other manufacturing information systems for quality prediction and operation control in metal-casting processes". For example, engine pistons are made from aluminum that is firstly heated and melted inside a furnace where additional elements are added to form an alloy. The molten alloy is then injected into a casting machine where it undergoes cooling and solidification and is transformed into a cast. This is followed by other stages, such as heat and surface treatments, machining and finally, assembly. To save time and prevent unnecessary machine operation hours, CPSs could be implemented to detect defects after each stage to automatically prevent defective products from going onto the next stage using machine vision [56]. According to Lee et al. [55], the main product defects in the aforementioned manufacturing process are generated in the metal casting process where more than $90 \%$ of these defects are due to cold shuts and bubbles. Knowing that these defects are mainly caused by temperature variations throughout the process, the authors proposed a CPS consisting of a K-type thermocouple sensor attached to the mold and connected to the controllers to collect the temperature of the casting process, combined with a programmable logic controller that collects other operational data, such as the time taken for the casting process to be completed. Data collected over a period of time was processed using a series of software that was able to achieve a defect prediction rate of $90 \%$ and reduce the total monthly operating hours by $18.5 \%$.

Externally, products are either tested individually or in batches after reaching the final form depending on their applications. Highly sophisticated products that have critical applications are usually tested individually to prevent any failures due to manufacturing faults and defects throughout its life span. For this reason, testing strategies similar to those of the wind tunnel highlighted earlier are used. However, due to the high cost of this technique and its very low efficiency in mass production testing, other forms are being implemented that provide autonomous testing and elimination of defective products. Another strategy is product health monitoring, which will be highlighted in Sect. 3.3.3.

\subsubsection{Machine Tools Health Monitoring}

Machine health monitoring in manufacturing facilities is essential for quality assurance and accuracy of the manufacturing parts [57]. Any unpredicted or sudden breakage of tools may cause a huge disturbance along the production line. Caggiano et al. [58] proposed a cloud-based CPS architecture for machine smart monitoring that aims to detect tool wear and tool breakage. Such systems can be divided into a cyber-physical based part and a cloud-based part, which will be discussed in a later section. The cyber-physical part consists of the physical machines including the tools used and the sensors. These sensors are usually dynamometers for measuring forces, accelerometers for measuring vibrations, electric current sensors, etc. These sensors are fitted to capture information for tool condition monitoring, such as the lathe-mounted multiple sensor system used for turning process monitoring [58]. Tool wear can be recognized by accelerometers that detect the increasing amplitude of vibrations that is caused by the accumulation of tool wear. Moreover, tool breakage can be also detected using an accelerometer attached at the tool shank, which has been proven to be the most suitable place for the sensor attachment. The accelerometer is very sensitive and could easily detect a change in the contact between the tool tip and work piece. A similar approach by Villalonga et al. (2018) includes the design of a condition-based monitoring architecture for $\mathrm{CNC}$ machine tools. This approach provides solutions to monitor the machine's elements and components and predicts failure patterns during the life cycle of the machine tool [58].

\subsubsection{Product Health Monitoring}

Product maintenance is one of the key factors to increasing the life span of any product. Automotive manufacturers set fixed time intervals for customers to bring in their cars for maintenance regardless of the condition of the car. This is considered a safety measure that is not only implemented in the automotive industry but also in the aerospace industry. Health monitoring of aircrafts is very critical and directly contributes to the safety of air travel. Yet many accidents occur due to faults and defects that are not discovered during maintenance. For example, an investigation of a fighter aircraft crash by Ejaz et al. (2007), discovered that the crash was due to the failure of the compressor rotor. A crack had initiated from machining marks on the disk then propagated along the machining mark causing fatigue [59]. 
A similar accident occurred due to fatigue in the central ball bearing of the compressor region that had been inspected five hours prior to the incident. The inspection showed that the "parameters measured was within the specified limits" [60].

The aerospace industry has had very noticeable improvements throughout the past decade. As seen earlier, inspection is not enough to label an aircraft safe to takeoff. CPS systems are now being implemented to provide pilots with real-time aircraft data monitoring. For example, Takeda et al. [61] proposed fiber Bragg grating (FBG) sensors for the long- term health monitoring of large-scale composite wing structures. By using FBG sensors, "the barely visible impact damages could be detected because the shape of the spectrum is severely distorted by the strain change due to the occurrence of damages". Applying CPSs not only on aircrafts but on any fatigue exposed structure could substantially decrease the risk of structural failure and allow real-time data to be presented to service centers. This means that aircrafts could be taken to maintenance centers whenever CPSs assess that it is required. As a result, this could prevent many accidents such as those mentioned earlier. Also different methods combining CPSs and AI for product inspection has been proposed such as using convolutional neural network (CNN) for inspecting method for defective casting products [62].

\subsubsection{Smart Factories}

Manufacturing is one of the highest energy consuming stages throughout the CE model. Currently, manufacturers are strongly leaning towards the adoption of energy saving strategies [63-66]. One way of approaching a low power consumption manufacturing model can be through CPSs. For example, a proposed CPS based on multi-agent system (CPMAS) technology produced an intelligent demand-side management system that was able to reduce power consumption by $35 \%$ in the month of July in a building of approximately $2800 \mathrm{~m}^{2}$. The proposed system relies intensively on the feedback loop of the CPS. The proposed system is composed of four different areas each with a specific task. These areas are the user area, the interface area, the analysis area, and the knowledge area. In general, sensors in the user area monitor the rooms and send data to the corresponding room agent in the interface area. This acts as an interface between the room and the system by producing detailed data of the user's habits. The data is then sent to the interface area where it is evaluated for the extraction of additional information. A proposed solution is then presented by each agent accordingly. If a critical condition is detected, it will be sent to the analysis area for the coach agent to evaluate proposed solutions and choose the most suitable one, which is sent back to the interface area. Lastly, the knowledge area stores the data related to power consumption, which includes solutions as well as the user's preferences from both areas, to deduce additional information [32]. Such systems can be implemented in manufacturing facilities on a larger scale that takes into consideration all the power equipment used in manufacturing as well as power consumption habits, such as cooling, heating, and lighting. Depending on the need, different sensors are placed in the user area, which contains rooms or sections in the manufacturing facility. The main task of the sensors is to obtain data from each room or section, such as recording temperatures throughout the day, measuring the light intensity and recording the user's preferences at different times. As mentioned earlier, the collected data is then sent to the corresponding room agent in the interface area that acts as an interface between the room and the system by producing detailed data of the workers' habits such as the preferred temperature, the light intensity, and the working times. The obtained data is then sent to the interface area where it is evaluated for the extraction of additional information, such as the number of people available at a specific time of the day. Moreover, CPS manufacturing architecture could provide self-predicting and self-aware machine health monitoring systems. This architecture acquires data needed to generate meaningful information and provide a decisionmaking process for the end user [38]. Hence, machine health monitoring data can be obtained directly from machines. These data are processed, and a proposed solution is then presented by each agent accordingly. For example, when the number of people in the room changes, the solution is to increase or decrease the cooling or heating depending on the season; when no people are in the room, the electricity is turned off, and so on. In the case of a critical condition being detected, such as a sudden breakdown of a machine, information is sent to the analysis area for the coach agent to evaluate proposed solutions. The coach agent chooses the most suitable solution and sends it back to the interface area, which acts accordingly by either solving the problem if it is solvable or involving a human factor by automatically emailing or messaging the designated engineers or supervisors on duty and notifying them about the critical case. Overall, this could substantially reduce the amount of energy by omitting the human factor from controlling the power consumption and relying on the smart CPS to optimize the use of energy without affecting the comfort of the employees. Moreover, machine health monitoring allows for early machine diagnoses that provide time for the manufacturers to find solutions and avoid delays that could be caused if the machines were to suddenly stop working due to undetected problems. Figure 9 presents a general model that is based on [32] using a schematic of the proposed agency with an emphasize on other CPS components, such as self-aware, self-predicting sensors, actuators, as well as a feedback loop [38]. 


\subsubsection{Smart Manufacturing Performance Measurement}

Smart manufacturing requires smart systems. CPSs are considered smart systems that integrate smart software applications with information and communication technologies that simultaneously optimize different performance metrics to deliver on-time, customized, high-quality products. In order to test and quantify the "smartness" of a manufacturing facility, specific performance metrics should be measured. Such performance criteria are productivity, quality, agility, and sustainability [67]. Most of these performance metrics can be easily collected and recorded using different types of sensors that can routinely collect all kinds of operational level data. This enables factories to have a real-time assessment of their production systems. Moreover, it is now possible to quantify the sustainability of manufacturing processes using CPSs that obtain the different measurements indicated by the "Standard Guide for the Definition, Selection, and Composition of Key Performance Indicators to Evaluate Environmental Aspects of Manufacturing Processes". Integrated CPSs then interpret the data and prepare a detailed report that includes all the parameters as well as efficiency scores

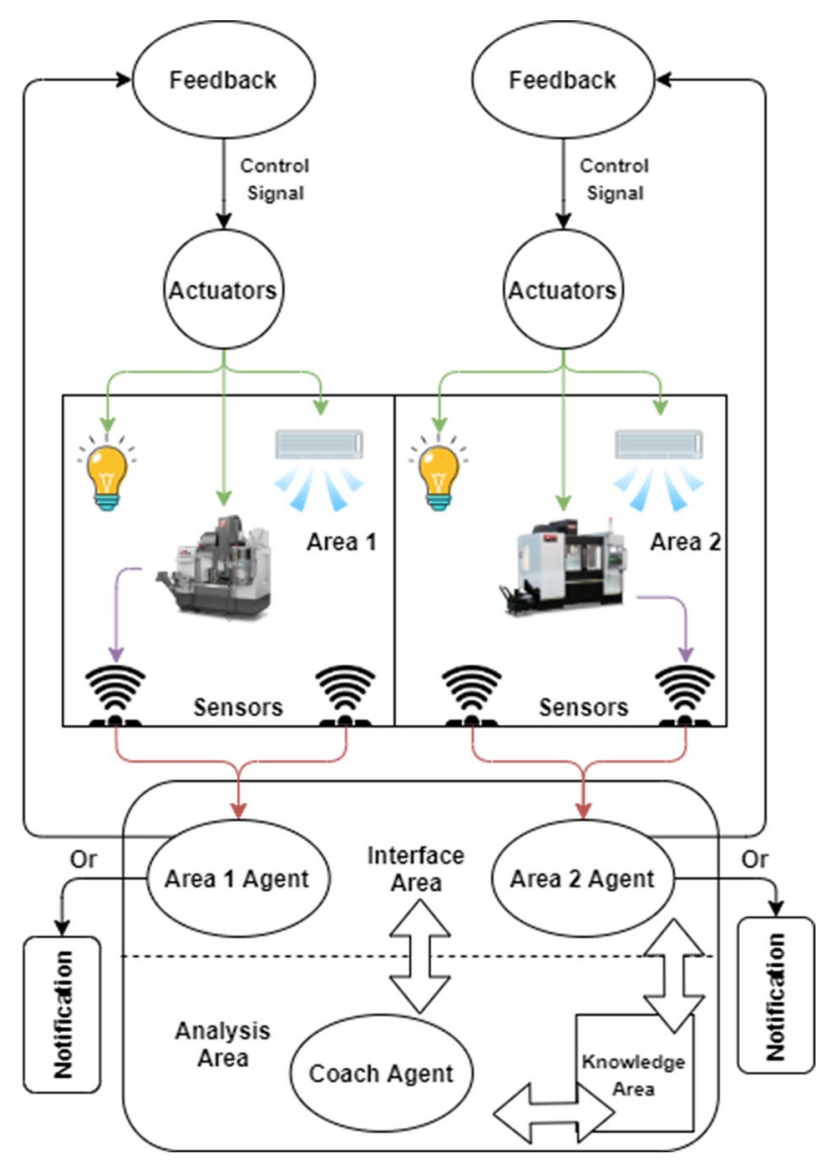

Fig. 9 Proposed CPS of a manufacturing facility based on the model used in [32] of different manufacturing processes, for manufacturers to act upon, so they can increase their sustainability score.

\subsubsection{Human-Robot Collaboration}

Many manufacturing tasks require the collaboration of humans and robots. This has been increasingly implemented in many assembly lines. Sometimes human brains are needed to perform some tasks. However, humans lack precision. To have both human brains and precision at the same time, CPSs could be the best solution manufacturers could use. For example, a symbiotic human-robot collaboration is another implementation of CPSs in manufacturing. In this situation human-robot interactions and collaborations are made possible in areas such as dynamic task planning. Robots can be instructed by humans using gestures, signs, or speech during tasks such as collaborative assembly. As a result, resource efficiency and productivity are enhanced $[31,43]$.

\subsubsection{Autonomous Mobile Material Handling Vehicles}

Moving parts and materials to their assigned assembly station in a safe and timely manner is one of the challenging logistical problems for most assembly lines and systems. Mass customization has made that task even more challenging since the right part should be delivered to the right assembly line at the right time. This task would require a huge labor force as well as sophisticated scheduling that is very hard to achieve manually [68]. CPSs provide a solution in the form of autonomous mobile material handling vehicles that are widely referred to as "Automatic Guided Vehicles" (AVGs). These autonomous vehicles are being implemented and are almost a standard device in most assembly lines. Generally, automating material logistics and scheduling in an assembly line ensures safe material handling, a fast response to customized orders, and achieves zero errors if correctly operated. There are many types of AVGs in the market today and each type carries out different tasks in a manufacturing facility. For example, there are automated lift trucks, platform AVGs, heavy load AVGs and AVGs for the automation of assembly lines. Similarly, autonomous vehicles are being widely used in warehouses for product distribution.

Some other applications of CPSs in manufacturing are cyber-physical modules for machine tools, plug-and-work applications, automated generation of process plans, scheduling with alternative routings in $\mathrm{CNC}$ workshops, adaptive scheduling through product-specific emergence data, cyber-physical support for maintenance strategies, and cross-company information exchange for an adaptive production control based on early warning information [51]. It can be noted that the number of applications of CPS in 
manufacturing is unlimited. This is mainly due to the flexibility of these systems.

\subsection{Distribution}

As mentioned earlier, distribution is an essential stage in any economy whether it is linear or circular. Suppliers must distribute their products in a timely manner without any delays. Many distributers already use different CPSs, such as ontime tracking systems. However, there is room for more. Most difficulties faced by distributers involve complex distribution and transportation networks, such as prior planning for drivers, and heavy traffic that can cause delays. These factors have a great impact on the environment and product distribution management.

\subsubsection{Using Unmanned Aerial Vehicles in Distribution}

To solve traffic jams for short distance deliveries, unmanned aerial vehicles (UAVs), more commonly called "drones," are a typical CPS [69] that can be used over short distances for low weight distributions. Using drones in deliveries eliminates many of the negative impacts a normal delivery would have on the environment. UAVs operating with clean energy, such as solar energy, would reduce carbon dioxide emissions caused by conventional means of delivery as well as save substantial time during peak hours [70]. The main problem associated with drone delivery systems is due to the limited payload. The payload is the load that the drone can lift. Usually, drones with a higher payload are bigger and more costly and their risk of falling or failing suddenly makes them unreliable for deliveries. Currently, Amazon aims to implement drone deliveries for packages that weigh 5 pounds $(2.268 \mathrm{~kg})$ or less, with an estimated delivery time of $30 \mathrm{~min}$ [71]. The technology is still in the research phase and has many constraints, such as regulations, safety, and most notably, the design of the drone itself. However, research in this field is evolving quickly with encouraging results that indicate that this promising technology might revolutionize logistics.

\subsubsection{Data Communication Virtual Platform}

Other challenges faced by suppliers and distributers are the complex production and transportation networks and the occurrence of disturbances. To overcome these problems, Farzzon et al. [72] presented a CPS improved supply chain model. The model highlights the use of CPSs in "data's communication virtual platform" which aims to represent a common world for suppliers, manufacturers, and distribution centers, permitting them to access different data regarding supply and demand as well as the available stock. In the proposed model the data flow between different stages of the distribution stage is facilitated by CPSs by providing a common data center.

\subsubsection{Path Decision Ant Colony Algorithm}

Another way of implementing CPSs in logistics is through the use of a CPS-oriented intelligent logistics path decision system [73]. The proposed system uses an algorithm called an "ant colony algorithm" (ACA). The system is derived from the behavior of ants foraging. Basically, ACA mimics how ants work using distribution centers as an ant nest where each ant is a distribution vehicle and the food for the ants serves as a distribution node. Ants determine the next distribution node based on the concentration of pheromones and the visibility of the path: the higher the visibility and the concentration of the pheromones, the shorter and more optimal the path is. Based on this, $\mathrm{P}$ indicates the probability of the next node being selected. A larger P indicates a greater possibility of being selected and a greater possibility of forming an optimal path. It should be noted that the virtual pheromones used in the algorithm have the same volatility as the pheromones released by ants. If a specific path is not being selected often, the pheromones will slowly evaporate leaving very low concentrations. This indicates that the path needs to be eliminated since it is not accessed often. In contrast, there will be more pheromones on a frequently accessed path, which indicates that this path is more convenient and more likely to become a distribution node. Similarly, ACA bases its selection of the optimal distribution path through different positive feedbacks. The collected positive feedbacks provide an iteration of the optimal. In the end, the optimal path is chosen by finding the optimal solution for the optimal choice of the logistics distribution path [73]. Through the use of such an algorithm, distributers could easily overcome the complexity of transportation routes saving substantial time, cutting down costs, and reducing greenhouse gas emissions.

\subsection{Usage}

Similar to manufacturing, consumers experience a handful of CPSs throughout their daily lives. The main purpose of using CPSs on the consumer level is to enhance their experiences with products by omitting simple but time-consuming tasks. Not only that, but CPS could also aid people with extensive spinal injuries by helping them to easily interact and merge with today's world of fast-growing technologies. Furthermore, CPSs provide a new means of health monitoring strategies in the form of portable devices. CPSs also help connect the usage stage to the rest of the CE stages, since most of the time the CE cycle ends at this stage due to the very limited interaction between consumers and other CE stages. 


\subsubsection{Neuralink}

People with extensive spinal injuries face many difficulties when interacting with today's technologies. Most of the time, simple tasks such as typing are considered difficult if not impossible. However, to make this possible, a bridge is needed to connect people with their devices without having them use their hands. For example, a person would be able to type without using the keyboard, would move the cursor without moving or touching the mouse, or even drive a car by just thinking about it. CPS has changed this from science fiction to reality. This can now be done using EEGbased non-invasive brain interfaces using neural implanting that would allow people to do various tasks by just thinking about them [27]. Announced by Facebook, the "typingby-brain" project promises to enable people to type a 100 words per minute [74], in contrast to the record of eight words per minute accomplished by Stanford University using a brain-computer interface [75]. Another initiative is the "Neuralink," which has an initial goal of helping people with extensive spinal injuries regain control of computers and mobile devises. In doing so, it Is hoped that various neurological disorders can be treated, and people will be able to communicate easily through text or speech synthesis, while sensory and movement function is restored and new ways of interactions both between humans and between humans and technology are created. This is accomplished through micron-scale threads that are inserted into areas of the brain that control movement. Each thread contains many electrodes and connects them to an implant called the Link, which is a sealed device that processes, stimulates, and transmits neural signals [76]. The potential implementations of such CPSs are enormous. For example, people could drive cars using their brains, which would significantly reduce the driver's reaction time since the car would respond directly to the driver's thoughts. When the technology is ready, it could be easily implemented in electric cars. Moreover, simple tasks such as recording an event on a calendar, controlling the TV, lights, heating, cooling etc. would be just a thought away.

\subsubsection{Portable Health Monitoring Devices}

Nowadays, sensors can be embedded into very small devices such as watches. Watches with sensors and computing capabilities are labeled as smart watches. Through these watches, a person can obtain a continuous reading of their sweat glucose [77] and measurements of physiological parameters, such as heart rate, galvanic skin resistance, and temperature [78]. As well they can monitor health in home-based dementia care [79], monitor respiratory rate and body position during sleep [80], monitor symptoms in advanced illness [81], and even detect the early symptoms of COVID-19 [82]. The capabilities of these devices are endless and are only constrained by innovations in the electromechanical field.

\subsubsection{Adaptable Electronics}

Smart electronics, such as televisions, smart phones, smart fridges, and smart homes, can easily adapt to the person using them. Motion sensors and accelerometers in smart phones detect and record movements throughout the day. This data is interpreted and is used to customize user experiences. For example, a smart phone is capable of understanding that you are having lunch by obtaining your location, the time of day, and your usual activities during the same time on previous days. Your phone could then send you a notification reminding you that it is lunch time and could even suggest a restaurant. The same applies to smart televisions that suggest movies based on previous activity and recorded preferences. Machine learning facilitated by CPSs provides a new means of people-machine interactions in the effort to create a smoother and friendly user experience.

\subsection{Recycling}

To maintain the circular nature of the economy, recycling should be optimized to return as much material as possible into the economy and reduce outputs to landfills. There have been many proposed waste collection processes that implement CPSs. Different papers have proposed CPSbased smart waste collection systems that integrate cyber and physical spaces to compute, control and communicate all components of waste management, while others have proposed CPS-based recovery methods for waste electrical and electronic equipment (WEEE) [83, 84]. Initially, a "digital twin" method was proposed by NASA [83]. Simply stated, "It indicates the simulation of an (aerospace) vehicle or system that uses the best available physical models, sensor updates, fleet history, etc." The main point of using a digital twin in WEEE management is to merge data from the physical world and the software system in the cyber world. However, the proposed idea requires an interactive collaboration between all stages of the $\mathrm{CE}$ with almost all Industry 4.0 enablers working simultaneously to serve its purpose. Hence this topic will be discussed further in the inter-impact section of this paper. Another approach aims to deploy CPS components, such as sensors and actuators, to improve the end-of-life processing of electrical and electronic equipment (EEE) [84]. This approach mainly relies on sensors, such as radio frequency identification tags (RFID), to allow the monitoring of waste throughout the waste management process. 


\subsubsection{Radio Frequency Identification (RFID) Waste Sorting System}

A full automation of the recycling process would require very smart and adaptive technologies. Waste sorting is a critical part in recycling. Each type of material needs to be treated differently. Aluminum cans are melted at very high temperatures, while doing the same to plastics poses high environmental and health risks due to the poisonous fumes that are emitted. Hence, it is critical to sort materials before applying any specific treatments. For that reason, radio frequency identification can be used. RFID is a tag that is very flexible and can vary in size and shape. These tags can store data that can be read when scanned by an RFID reader. RFID readers can be attached to sorting machines, which can then read the data from each object to identify its material, thus making it easier for the machine to sort. For example, aluminum cans can be easily identified. WEEE can also be easily identified. Organic materials will not usually have these chips so it can be sent directly to farmers to use as fertilizers. Moreover, this also ensures that medical waste is treated separately and with extra care and that industrial materials are returned to manufacturers for remanufacturing and reuse. There are available waste sorting techniques and machines; however, these machines are not efficient when exposed to mixed waste and only work with bulk. Hence, CPSs would provide an easily implemented and efficient solution for waste sorting and management.

\section{Sustainable Development Goals}

Sustainable development goals (SDGs) are 17 interlinked goals set by the United Nations in 2015 and are designed to "promote prosperity while protecting the planet. They recognize that ending poverty must go hand-in-hand with strategies that build economic growth and address a range of social needs including education, health, social protection, and job opportunities, while tackling climate change and environmental protection" [85]. Summarized in Table 2, this section presents how each technology discussed earlier within each CE stage contributes to different SDG.

\subsection{Sourcing}

The automation of mining in the sourcing stage directly achieves the third goal as its main goal is to ensure a safe working environment by eliminating risk factors in the mining process. The implementation of CPSs in the sourcing stage also contributes to the eighth goal as it eradicates forced labor, slavery, and human trafficking by eliminating the human factor in the mining process. As a result, it promotes decent work and economic growth. It also directly achieves the ninth goal of industry: innovation and infrastructure. An important advantage for automation of the mining stage is a significant reduction in inequality, mainly in the form of gender inequality, as the physical factor, in which males usually dominate, is eliminated since the mining processes are controlled through computers. Hence, automation of the mining stage has a direct impact on fifth SDG goal as well.

\subsection{Design}

The design stage targets several SDGs as it determines how the product will be manufactured, used, and disposed. Firstly, the design information feedback system achieves the ninth goal of Industry, innovation and infrastructure, and the twelfth goal of reasonable consumption and production since data and knowledge is used to verify the final design of the products before approval; thus, fewer malfunctioning products are manufactured. Energy savings, cost reductions, and an increase in the lifetime of the products and goods are achieved. As a result, it indirectly contributes to attaining a sustainable environment, which is the eleventh SDG. Similarly, testing and simulation assistance in product designs achieve the same goals. The use of simulations reduces emissions caused by actual testing of sophisticated products such as planes or cars. Most of the time, individual parts can be tested in a controlled environment without the need of real-time operation. This directly contributes to the thirteenth goal of climate action. Design for manufacturing and assembly also targets the 9th, 11th 12th and 13th goals for similar reasons. In addition, through the elimination of many unnecessary materials and manufacturing processes, the stress on the environment is reduced, thus indirectly contributing to the 14th and 15th goals of life below water and life on land, respectively. Moreover, it provides the easiest, cheapest, and most efficient route for product manufacturing and assembly contributing directly to the decent work and economic growth. Overall, the design stage in a CE can achieve at least seven of the SDGs.

\subsection{Manufacturing}

The manufacturing stage contributes to the most goals among the CE stages. It is safe to say that all the CPS technologies in this stage achieve the ninth goal. It can be observed that the implementation of CPSs in this stage contributes either directly or indirectly to the good health and well-being of employees and customers, thus achieving the third goal. Similar to automation in the sourcing stage, manufacturing process automation also contributes to the fifth and tenth goals of gender equality and reduced inequalities, respectively. Moreover, since smart factories 
Table 2 SDGs achieved by the implementation of different CPSs within each of the CE stages

\begin{tabular}{|c|c|c|c|c|c|c|c|c|c|c|c|c|c|c|c|c|c|c|}
\hline \multirow[b]{2}{*}{$\begin{array}{l}\text { Circular Economy } \\
\text { Stage }\end{array}$} & \multirow[b]{2}{*}{ Implementation } & \multicolumn{17}{|c|}{ Sustainable Development Goals (SDGs) } \\
\hline & & 1 & 2 & 3 & 4 & 5 & 6 & 7 & 8 & 9 & 10 & 11 & 12 & 13 & 14 & 15 & 16 & 17 \\
\hline Sourcing & $\begin{array}{c}\text { Autonomous mining } \\
\text { operations }\end{array}$ & - & - & $\mathbf{x}$ & - & $\mathbf{x}$ & - & - & $\mathbf{x}$ & $\mathbf{x}$ & $\mathbf{x}$ & - & - & - & - & - & - & - \\
\hline \multirow{3}{*}{ Designing } & $\begin{array}{c}\text { Design information feedback } \\
\text { system }\end{array}$ & - & - & - & - & - & - & - & - & $\mathbf{x}$ & - & 0 & $\mathbf{x}$ & - & - & - & - & - \\
\hline & $\begin{array}{c}\text { Testing and simulation } \\
\text { assistance in product design }\end{array}$ & - & - & - & - & - & - & - & - & $\mathbf{x}$ & - & 0 & $\mathbf{x}$ & $\mathbf{x}$ & - & - & - & - \\
\hline & $\begin{array}{c}\text { Design for manufacturing and } \\
\text { assembly }\end{array}$ & - & - & - & - & - & - & - & $\mathbf{x}$ & $\mathbf{x}$ & - & $\mathbf{x}$ & $\mathbf{x}$ & $\mathbf{x}$ & 0 & 0 & - & - \\
\hline \multirow{7}{*}{ Manufacturing } & $\begin{array}{l}\text { Quality control and quality } \\
\text { assurance }\end{array}$ & - & - & $\mathbf{x}$ & - & - & 0 & - & - & $\mathbf{x}$ & - & $\mathbf{x}$ & $\mathbf{x}$ & - & - & - & - & - \\
\hline & $\begin{array}{l}\text { Machine tools health } \\
\text { monitoring }\end{array}$ & - & - & 0 & - & - & - & - & - & $\mathbf{x}$ & - & - & $\mathbf{x}$ & - & - & - & - & - \\
\hline & Products health monitoring & - & - & 0 & - & - & - & - & - & $\mathbf{x}$ & - & - & $\mathbf{x}$ & - & - & - & - & - \\
\hline & Smart factories & - & - & $\mathbf{x}$ & - & - & - & $\mathbf{x}$ & - & $\mathbf{x}$ & - & $\mathbf{x}$ & $\mathbf{x}$ & $\mathbf{x}$ & 0 & 0 & - & - \\
\hline & $\begin{array}{c}\text { Smart manufacturing } \\
\text { performance measurement }\end{array}$ & - & - & $\mathbf{x}$ & - & - & - & $\mathbf{x}$ & - & $\mathbf{x}$ & - & $\mathbf{x}$ & $\mathbf{x}$ & $\mathbf{x}$ & 0 & 0 & - & - \\
\hline & Human-robot collaboration & - & - & $\mathbf{x}$ & - & $\mathbf{x}$ & - & - & - & $\mathbf{x}$ & $\mathbf{x}$ & - & - & - & - & - & - & - \\
\hline & $\begin{array}{c}\text { Autonomous mobile material } \\
\text { handling vehicles }\end{array}$ & - & - & $\mathbf{x}$ & - & - & - & - & - & $\mathbf{x}$ & - & - & - & - & - & - & - & - \\
\hline \multirow{3}{*}{ Distribution } & $\begin{array}{l}\text { Using unmanned aerial } \\
\text { vehicle in distribution }\end{array}$ & - & - & - & - & $\mathbf{x}$ & - & - & - & $\mathbf{x}$ & $\mathbf{x}$ & $\mathbf{x}$ & - & $\mathbf{x}$ & $\mathbf{x}$ & $\mathbf{x}$ & - & - \\
\hline & $\begin{array}{l}\text { Data communication virtual } \\
\text { platform }\end{array}$ & - & - & - & - & - & - & - & - & $\mathbf{x}$ & - & $\mathbf{x}$ & - & - & - & - & - & - \\
\hline & $\begin{array}{l}\text { Path decision ant colony } \\
\text { algorithm }\end{array}$ & - & - & $\mathbf{x}$ & - & - & - & - & - & $\mathbf{x}$ & - & - & - & $\mathbf{x}$ & 0 & 0 & - & - \\
\hline \multirow{3}{*}{ Usage } & NeuraLink & - & - & $\mathbf{x}$ & $\mathbf{x}$ & - & - & - & - & $\mathbf{x}$ & - & - & - & - & - & - & - & - \\
\hline & $\begin{array}{c}\text { Health monitoring portable } \\
\text { devices }\end{array}$ & - & - & $\mathbf{x}$ & - & - & - & - & - & $\mathbf{x}$ & - & - & - & - & - & - & - & - \\
\hline & Adaptable electronics & - & - & 0 & $\mathbf{x}$ & - & - & - & - & $\mathbf{x}$ & - & $\mathbf{x}$ & - & - & - & - & - & - \\
\hline Recycling & $\begin{array}{l}\text { Radio frequency identification } \\
\text { (RFID) waste sorting system }\end{array}$ & - & - & - & - & - & - & - & - & $\mathbf{x}$ & - & $\mathbf{x}$ & - & $\mathbf{x}$ & $\mathbf{x}$ & $\mathbf{x}$ & - & - \\
\hline
\end{tabular}

(x) directly achieved, (0) indirectly achieved

and smart performance measurements serve the same purpose, both achieve the same SDGs which are the $3 \mathrm{rd}, 7 \mathrm{th}$, 9th, 11th, 12th, and 13th goals, while indirectly contributing to the 14 th and the 15 th goals. This is mainly due to the intense reliance of smart factories on clean energy for operations. As well, this can be integrated into smart and sustainable cities, with reasonable on-demand production that include highly efficient and clean production systems. This reduces greenhouse gas emissions and subsequently, the stress on life both on land and below the water. Overall, applying CPSs in manufacturing in a CE can achieve at least ten of the SDGs.

\subsection{Distribution}

Similar to the manufacturing stage, the ninth SDG can also be considered a common achievable goal among the implementation of different CPSs in the distribution stage. Moreover, the use of UAVs eliminates inequalities as its operation can be done using controllers or built-in algorithms, which can be handled by people with disabilities. If UAVs use electricity generated from clean energy, they would directly achieve goals 14, 15 and 16 . To continue, the path decision of the ant colony algorithm chooses the most convenient, safest and shortest paths for drivers to follow, thus achieving the $3 \mathrm{rd}, 13 \mathrm{th}, 14 \mathrm{th}$, and 15 th SDGs. In addition to the ninth 
SDG, the data communication virtual platform achieves the eleventh goal through enabling a common data sharing platform that allows multiple vendors and distributors to manage inventories in a sustainable manner.

\subsection{Usage}

Several CPSs can be deployed to achieve certain SDGs at the usage stage. For example, Neuralink and different portable health monitoring devices directly contribute to the third SDG of good health and wellbeing. Neuralink and adaptable electronics can also contribute to the fourth SDG if utilized in education by either helping people with severe spinal injuries with their education or personalizing education based on a pupil's needs and interests. With regards to the product, however, the user determines if it will achieve different SDGs by how it is used and disposed of. This is unlike the service point of view discussed earlier, in which the technology determines the goals to be achieved.

\subsection{Recycling}

The projected recycling stage would serve its purpose by returning the materials into the CE. The use of RFID tags could significantly enhance and increase the efficiency of the recycling process, which would directly contribute to the enhancement of the circular economy and achieve the eleventh SDG: sustainable cities and communities. Recycling also contributes to the thirteenth SDG (climate action) by reducing mining and different manufacturing processes needed to make new products. Eventually, greenhouse gas emissions would be lowered and waste disposal in the seas decreased, protecting the lives of different species under the sea and on land as targeted in the fourteenth and fifteenth SDGs.

\section{CE Assessment Tool}

The adoption of an I4.0 enabled CE has been proven to be an effective solution in tackling many of modern-day accumulated complications caused by industrialization and human activities since the first industrial revolution in the seventeenth century. Many developed countries have shifted from the linear conventional economy model to a CE model. With its economic, social, and environmental benefits, many developing nations are to follow. With such foundations, nations could easily improve their wealth, prosperity, and abundance. However, to what extent can the implementation of these tools contribute to the CE?

As reviewed earlier, I4.0 effectively contribute to the circularity of the economy. Many other procedures, standards, and factors also play an important role in determining the circularity of the economy. However, depending on each individual case, some factors may impact the circularity more than other. As stressed by the economist Peter Drucker, improvement, or manageability of a system, implies the measurability of that system [86]. In order to be able to capture the progress made towards circularity, an assessment tool should be established. For it to be effective, it should be able to measure the effectiveness of the $\mathrm{CE}$ of a wide range of sectors. So far, there are no common accepted procedures to measure CE performance [87]. Literature shows that deep research on CE assessment tools and indicators is still lacking [88]. Also, there is a need to establish a set of indicators to monitor the transition to CE [89]. Very few CE indicators frameworks are available, most of them fail to capture some important dimensions such as policy implementation towards CE [90]. Literature lacks a comprehensive scaling/rating system that accounts for all $\mathrm{CE}$ dimensions including non-manufacturing ones such as customers' contributions, policies, regulations, and technological advancements.

An effort was made by Sassanelli et al. to highlight different assessment tools in a systematic literature review that showed some potential in this field [86]. However, none of the presented assessment procedures are comprehensive, many fail to capture all the dimensions of the CE at once, and many others are subjective. To illustrate, there are several tools intended to assess the CE performance on different scales. A well-known tool is Circulytics ${ }^{\circledR}$ by the Ellen Macarthur Foundation [91]. The tool measures the CE performance of company's material and water flow and other services provided along with energy use. This tool however is a company-level (micro-level) measuring tool and cannot be implemented on other CE levels such as the macro and meso levels. Also, the tool requires direct input from users, which adds an undesirable level of subjectivity to the results. Another assessment tool is the Cradle to Cradle Certified ${ }^{\circledR}$ by the Cradle-to-Cradle Products Innovation Institute [92]. Similarly, the tool is used to assess products made for the CE (micro level) and cannot be used on the macro or meso levels. Moreover, the tool lacks flexibility even on the product level as it does not assess products that consumes nuclear energy or uses non-renewable resources. Another tool proposed by Chun-ron et al., assesses regional CE based on matter element analysis [93]. Like the previous tools, it only assesses CE on a meso scale and uses a basic grading system. IFIXIT is another tool that assesses the repairability of mobile devices, which directly contributes to the recycling stage of the CE, based on a specified criterion. This score however cannot be used individually to assess circulatory of mobile devices but gives valuable insights on whether the device can fit into a CE or not. Table 3 presents the previously discussed assessment tools along with their limitations. 
Table $3 \mathrm{CE}$ assessment tools available and their limitations

\begin{tabular}{|c|c|c|}
\hline Source & Assessment tool & Limitations \\
\hline Ellen MacArthur Foundation [90] & Circulytics $^{\circledR}$ & $\begin{array}{l}\text { Not a comprehensive tool, compatible for measuring companies CE } \\
\text { performances only (micro-level) }\end{array}$ \\
\hline $\begin{array}{l}\text { Cradle to Cradle Products Innova- } \\
\text { tion Institute [91] }\end{array}$ & Cradle to Cradle Certified ${ }^{\circledR}$ & $\begin{array}{l}\text { Not a comprehensive tool, compatible for measuring products CE } \\
\text { performances only (micro-level) } \\
\text { Does not assess products that consumes nuclear energy or uses non- } \\
\text { renewable resources }\end{array}$ \\
\hline Chun-rong et al. [92] & $\begin{array}{l}\text { Evaluation of Regional Circular } \\
\text { Economy Based on Matter Element } \\
\text { Analysis }\end{array}$ & $\begin{array}{l}\text { Not a comprehensive tool, compatible for measuring CE perfor- } \\
\text { mances regionally only } \\
\text { Basic grading system }\end{array}$ \\
\hline IFIXIT [93] & IFIXIT & $\begin{array}{l}\text { Measures mobile devices circulatory only (micro-level) } \\
\text { Cannot be used alone to assess the circulatory of the devices }\end{array}$ \\
\hline
\end{tabular}

It can be noticed that a standardized comprehensive $\mathrm{CE}$ measuring or rating system is needed to allow businesses on different levels of the economy improve their circulatory. Such a system would facilitate the adoption of a standardized data collection and information management sharing systems that would ease the collaborations between different firms along the CE. To conclude, in order to correctly capture and measure circularity, the CE assessment tool should be flexible with a wide range of indicators that would be capable of measuring the circulatory of countries, sectors, companies or products [94].

\section{Summary and Future Outlook}

This paper presents a review on the implementation and integration of CPSs in each of the CE stages, highlights the SDGs that would be achieved as a result, and reviews the current state of the $\mathrm{CE}$ assessment tools. The findings of the paper are presented below:

- All six stages of the CE have a great potential to integrate CPSs within them.

- Autonomous mining in the sourcing stage provides a safe and efficient working environment and achieves five different SDGs.

- There are many possible implementations of CPSs in the design stage, such as in design information feedback systems, in testing and simulation assistance in product designs, and in designs for manufacturing and assembly. These systems directly achieve five SDGs and indirectly achieve two SGDs.

- The impact of CPSs in the manufacturing stage is enormous with vast room for implementation, such as in smart factories, QC and QA, health monitoring of machines and products, and many more. More than half of the SDGs can be achieved through the implementation of different CPSs in this stage.
- The integration of CPSs in the distribution stage can result in several implementations, such as the development of the path decision ant algorithm, UAVs, and virtual data communication platforms. Together, these applications contribute to seven different SDGs.

- In the usage stage, the implementation of CPSs can be at the product level or the consumer level. Some of these applications include adaptable electronics and portable health monitoring devices. Four different SDGs are achieved through the applications presented.

- Using RFID in recycling would facilitate the connection between this stage and different stages along the CE. On its own, it achieves five different SDGs.

Moreover, this review highlighted the need of an assessment tool that measures the circulatory on different scales of the economy (micro, meso and macro). It can be concluded that the area of $\mathrm{CE}$ assessment tools lack the following: (1) A comprehensive I4.0 tools guide to facilitate and ease their implementation along the CE; (2) A universal tool to assess the readiness of a facility or a country to adopt a $\mathrm{CE}$ model and grade it based on the efficiency of adoption, the overall products quality of the products, and the potential improvements, and (3) A set of measures and standards to qualify SDG achievements and act as a guideline for different operations. Also, it is important to establish indicators' databases by experts of different industries to support and ease the transition to CE. Finally, there is a need to provide similar review on other I4.0 tools as these technologies have wide applications and capabilities that have not been fully investigated on the CE scale.

Acknowledgements The authors would like to acknowledge the American University of Sharjah for funding this work under grants FRG19M-E78 and EFRG18-MSE-CEN-26

Funding The authors would like to acknowledge the American University of Sharjah for funding this work under grants FRG19-M-E78 and EFRG18-MSE-CEN-26. 
Availability of data and material Not applicable.

Code availability Not applicable.

\section{Declarations}

Conflicts of interest The authors declare that they have no known competing financial interests or personal relationships that could have appeared to influence the work reported in this paper.

Ethics approval Not applicable.

Consent to participate Not applicable.

Consent for publication All authors have accepted to publish this work in a journal article.

\section{References}

1. United Nations. (2019). Department of Economic and Social Affairs. World Population Prospects 2019. United Nations.

2. U.S. Energy Information Administration (EIA). (2019). International Energy Outlook 2019. U.S. Energy Information Administration.

3. Intergovernmental Panel of Climate Change. (2015). Climate change 2014: Synthesis report. IPCC.

4. Ritchie, H., \& Roser, M. (2018). $\mathrm{CO}_{2}$ emissions. [Online]. https:// ourworldindata.org/co2-emissions

5. Ritchie, H., \& Roser, M. (2016). Emissions by sector. [Online]. https://ourworldindata.org/emissions-by-sector

6. World Meteorological Organization (WMO). (2020). WMO Statement on the State of the Global Climate in 2019. World Meteorological Organization.

7. United States Environmental Protection Agency. (2019). Facts and figures about materials, waste and recycling. [Online]. https:// www.epa.gov/facts-and-figures-about-materials-waste-and-recyc ling/national-overview-facts-and-figures-materials\#: :text=In $\%$ $202018 \% 2$ C\%20about $\% 20146.2 \% 20$ million,less $\% 20$ than $\% 2010 \%$ 20percent $\% 20$ each

8. Ghosh, S. K. (2020). Introduction to circular economy and summary analysis of chapters. In Circular economy: Global perspective (pp. 1-23). Springer; 2020

9. Ellen MacArthur Foundation. (2013). Towards the circular economy. Ellen MacArthur Foundation.

10. Fan, Y., \& Fang, C. (2020). Circular economy development in China-current situation, evaluation and policy implications. Environmental Impact Assessment Review, 84, 106441.

11. Ghisellini, P., Cialani, C., \& Ulgiati, S. (2016). A review on circular economy: the expected transition to a balanced interplay of environmental and economic systems. Journal of Cleaner Production, 114, 11-32.

12. United Nations. (1987). Our common future: Report of the World Commission on Environment and Development (Brundtland Report). United Nations.

13. United Nations. (2002). Report of the World Summit on Sustainable development. United Nations.

14. Geissdoerfer, M., Savaget, P., Bocken, N. M., \& Hultink, E. J. (2017). The circular economy-A new sustainability paradigm? Journal of Cleaner Production, 143, 757-768.

15. Schröder, P., Bengtsson, M., Cohen, M., Dewick, P., Hofstetter, J., \& Sarkis, J. (2019). Degrowth within-Aligning circular economy and strong sustainability narratives. Resources, Conservation \& Recycling, 146, 190-191.

16. Acerbi, F., \& Taisch, M. (2020). A literature review on circular economy adoption in the manufacturing sector. Journal of Cleaner Production. https://doi.org/10.1016/j.jclepro.2020. 123086.

17. Tolio, T., Bernard, A., Colledani, M., Kara, S., Seliger, G., Duflou, J., Battaia, O., \& Takata, S. (2017). Design, management and control of demanufacturing and remanufacturing systems. CIRP Annals-Manufacturing Technology, 66, 585-609.

18. McKinsey Center for Business and Environment. (2015). Europe's circular-economy opportunity. McKinsey \& Company.

19. Schulze, G. (2016). Growth within: A circular economy vision for a competitive Europe. Ellen MacArthur Foundation.

20. D'Amato, D., \& Korhonen, A. T. J. (2019). Circular, green, and bio economy: How do companies in land-use intensive sectors align with sustainability concepts? Ecological Economics, 158, $116-133$.

21. Lund, E. (2021, March). Packaging in the circular economy (Lazard). Retrieved from https://www.lazardassetmanagement. com/at/en_uk/references/fundamental-focus/packaging-in-thecircular-economy

22. Park, K. T., Kang, Y. T., Yang, S. G., Zhao, W. B., Kang, Y.-S., Im, S. J., Kim, D. H., Choi, S. Y., \& Noh, S. D. (2020). Cyber physical energy system for saving energy of the dyeing process with industrial internet of things and manufacturing big data. International Journal of Precision Engineering and Manufacturing-Green Technology, 7, 219-238.

23. Kim, D.-H., Kim, T. J. Y., Wang, X., Kim, M., Quan, Y.-J., Oh, J. W., Min, S.-H., Kim, H., Bhandari, B., Yang, I., \& Ahn, S.-H. (2018). Smart machining process using machine learning: A review and perspective on machining industry. International Journal of Precision Engineering and Manufacturing-Green Technology, 5, 555-568.

24. Kerin, M., \& Pham, D. T. (2019). A review of emerging industry 4.0 technologies in remanufacturing. Journal of Cleaner Production, 237, 117805.

25. Sarc, R., Curtis, A., Kandlbauer, L., Khodier, K., Lorber, K., \& Pomberger, R. (2019). Digitalisation and intelligent robotics in value chain of circular economy oriented waste managementA review. Waste Management, 95, 476-492.

26. Dantas, T., de-Souza, E., Destro, I., Hammes, G., Rodriguez, C., $\&$ Soares, S. (2021). How the combination of Circular Economy and Industry 4.0 can contribute towards achieving the Sustainable Development Goals. Sustainable Production and Consumption, 26, 213-227.

27. Gupta, G., Pequito, S., Bogdan, P. (2018). Re-thinking EEGbased non-invasive brain interfaces: Modeling and analysis. In 2018 9th ACM/IEEE international conference on cyber-physical systems.

28. Khan, I. S., Ahmad, M. O., \& Majava, J. (2021). Industry 4.0 and sustainable development: A systematic mapping of triple bottom line, Circular Economy and Sustainable Business Models perspectives. Journal of Cleaner Production, 297, 126655.

29. Leng, J., Ruan, G., Jiang, P., Xu, K., Liu, Q., Zhou, X., \& Liu, C. (2020). Blockchain-empowered sustainable manufacturing and product lifecycle management in industry 4.0: A survey. Renewable and Sustainable Energy Reviews, 132, 110112.

30. Boulila, N. (2019). Cyber-physical systems and Industry 4.0: Properties, structure, communication, and behavior, Munich.

31. Wang, L., Törngren, M., \& Onori, M. (2015). Current status and advancement of cyber-physical systems in manufacturing. Journal of Manufacturing Systems, 37, 517-527.

32. Amato, A., Quarto, A., \& Lecce, V. D. (2020). An application of cyber-physical system and multi-agent technology to demand-side management systems. Pattern Recognition Letters, 141, 23-31. 
33. Wu, N., \& Li, X. (2011). RFID applications in cyber-physical system. In RFID applications in cyber-physical system, deploying RFID-Challenges, solutions, and open issues. IntechOpen.

34. Uckelmann, D., Harrison, M., \& Michahelles, F. (2011). An architectural approach towards the future internet of things. In Architecting the internet of things (pp. 1-24).

35. Greer, C., Burns, M., Wollman, D., \& Griffor, E. (2019). Cyber-physical systems and internet. NIST Special Publication 1900-202.

36. Kristoffersen, E., Blomsma, F., Mikalefa, P., \& Li, J. (2020). The smart circular economy: A digital-enabled circular strategies framework for manufacturing companies. Journal of Business Research, 120, 241-261.

37. Bag, S., Yadav, G., Wood, L. C., Dhamija, P., \& Joshi, S. (2020). Industry 4.0 and the circular economy: Resource melioration in logistics. Resources Policy, 68, 101776.

38. Bagheri, B., Yang, S., Kao, H.-A., Kao, H.-A., \& Lee, J. (2015). Cyber-physical systems architecture for self-aware machines in Industry 4.0 environment. In International federation of automation control.

39. Jabbour, A. B. L. S., Jabbour, C. J. C., Filho, M. G., \& Roubaud, D. (2018). Industry 4.0 and the circular economy: A proposed research agenda and original roadmap for sustainable operations. In Big data analytics in operations \& supply chain management (pp. 273-286).

40. Dev, N. K., Shankar, R., \& Qaiser, F. H. (2020). Industry 4.0 and circular economy: Operational excellence for sustainable reverse supply chain performance. Resources, Conservation \& Recycling, 153, 104583.

41. Rajput, S., \& Singh, S. P. (2018). Industry 4.0-Challenges to implement circular economy. Benchmarking: An International Journal.

42. Neto, H. F. S., Pereira, W. V. S., Dias, Y. N., Souza, E. S., Teixeira, R. A., Lima, M. W., Ramos, S. J., Amarante, C. B., \& Fernandes, A. R. (2020). Environmental and human health risks of arsenic in gold mining areas in the eastern Amazon. Environmental Pollution, 265, 114969.

43. Wang, X. V., Kemény, Z., Váncza, J., \& Wang, L. (2017). Human-robot collaborative assembly in cyber-physical production: Classification framework and implementation. CIRP Annals-Manufacturing Technology, 66, 5-8.

44. Torn, I., \& Vaneker, T. (2019). Mass Personalization with Industry 4.0 by SMEs: A concept for collaborative networks. Procedia Manufacturing, 28, 135-141.

45. Brandmeier, M., Bogner, E., Brossog, M., \& Franke, J. (2016). Product design improvement through knowledge feedback of cyber-physical systems. Procedia CIRP, 50, 186-191.

46. Brandmeier, M., Bogner, E., Brossog, M., \& Franke, J. (2016). Product design improvement through knowledge feedback of cyber-physical systems. Reprinted from Procedia CIRP 50. Copyright (2016), with permission from Elsevier.

47. Cattafesta, L., Bahr, C., \& Mathew, J. (2010). Fundamentals of wind-tunnel design. In Encyclopedia of aerospace engineering. Wiley.

48. PBC. [Online]. https://www.pcb.com/Contentstore/mktgcontent/ LinkedDocuments/Aerospace/AD_WindTunnel_LOWRES.pdf

49. Gatech. [Online]. https://me.gatech.edu/files/capstone/L071M E4182DFA

50. Rolls Royce. (2019). [Online]. http://rolls-royce.com/ /media/ Files/R/Rolls-Royce/documents/sustainability/value-chaincompetitiveness/7-vcc-how-to-design-for-manufacture-andassembly.pdf

51. Monostori, L., Kádár, B., Bauernhansl, T., Kondoh, S., Kumara, S., Reinhart, G., Sauer, O., Schuh, G., Sihn, W., \& Sihn, W. (2016). Cyber-physical systems in manufacturing. CIRP AnnalsManufacturing Technology, 65, 621-641.
52. Kang, H. S., Lee, J. Y., Choi, S., Kim, H., Park, J. H., Son, J. Y., Kim, B. H., \& Noh, S. D. (2016). Smart manufacturing: Past research, present findings, and future directions. International Journal of Precision Engineering and Manufacturing-Green Technology, 3, 111-128.

53. Park, K. T., Lee, D., \& Noh, S. D. (2020). Operation procedures of a work-center-level digital twin for sustainable and smart manufacturing. International Journal of Precision Engineering and Manufacturing-Green Technology, 7, 791-814.

54. Pham, A. D., \& Ahn, H. J. (2018). High precision reducers for industrial robots driving 4th industrial revolution: State of arts, analysis, design, performance evaluation and perspective. International Journal of Precision Engineering and ManufacturingGreen Technology, 5, 519-533.

55. Lee, J., Noh, S. D., Kim, H. J., \& Kang, Y. S. (2018). Implementation of cyber-physical production systems for quality prediction and operation control in metal casting. Sensors (Basel, Switzerland), 18(5), 1428. https://doi.org/10.3390/s18051428.

56. Ren, Z., Fang, F., Yan, N., \& Wu, Y. (2021). State of the art in defect detection based on machine vision. International Journal of Precision Engineering and Manufacturing-Green Technology.

57. Bahçe, E., \& Özdemir, B. (2021). Burr measurement method based on burr surface area. International Journal of Precision Engineering and Manufacturing-Green Technology, 8, 1287-1296.

58. Caggiano, A., Segreto, T., \& Teti, R. (2016). Cloud manufacturing framework for smart monitoring of machining. Procedia CIRP, 55, 248-253.

59. Ejaz, N., Salam, I., \& Tauqir, A. (2007). An air crash due to failure of compressor rotor. Engineering Failure Analysis, 14, 831-840.

60. Salam, I., Tauqir, A., Haq, A. U., \& Khan, A. Q. (1998). An air crash due to fatigue failure of a ball bearing. Engineering Failure Analysis, 5, 261-269.

61. Takeda, S., Aoki, Y., Ishikawa, T., Takeda, N., \& Kikukawa, H. (2007). Structural health monitoring of composite wing structure during durability test. Composite Structures, 79, 133-139.

62. Nguyen, T. P., Choi, S., Park, S.-J., Park, S. H., \& Yoon, J. (2021). Inspecting method for defective casting products with convolutional neural network (CNN). International Journal of Precision Engineering and Manufacturing-Green Technology, 8, 583-594.

63. Raileanu, S., Anton, F., Iatan, A., Borangiu, T., Anton, S., \& Morariu, O. (2017). Resource scheduling based on energy consumption for sustainable manufacturing. Journal of Intelligent Manufacturing, 28, 1519-1530.

64. Müller, J. M., \& Voigt, K.-I. (2018). Sustainable industrial value creation in SMES: A comparison between Industry 4.0 and made in China 2025. International Journal of Precision Engineering and Manufacturing-Green Technology, 5, 659-670.

65. Liu, N., Zhang, Y. F., \& Lu, W. F. (2019). Improving energy efficiency in discrete parts manufacturing system using an ultraflexible job shop scheduling algorithm. International Journal of Precision Engineering and Manufacturing-Green Technology, 6, 349-365.

66. Dornfeld, D. A. (2014). Moving towards green and sustainable manufacturing. International Journal of Precision Engineering and Manufacturing-Green Technology, 1, 63-66.

67. Feeney, A. B., Frechette, S., \& Srinivasan, V. (2017). Cyber-physical systems engineering for manufacturing. In Springer series in wireless technology, industrial internet of things: Cyber manufacturing systems, Gaithersburg.

68. Cohen, Y., Faccio, M., Pilati, F., \& Yao, X. (2019). Design and management of digital manufacturing and assembly systems in the Industry 4.0 era. The International Journal of Advanced Mапиfacturing Technology, 105, 3565-3577. 
69. Goncalves, F. S., Raffo, G. V., \& Becker, L. B. (2016). Managing CPS complexity: Design method for unmanned aerial vehicles. In IFAC.

70. Goodchild, A., \& Toy, J. (2018). Delivery by drone: An evaluation of unmanned aerial vehicle technology in reducing $\mathrm{CO} 2$ emissions in the delivery service industry. Transportation Research Part D, 61, $58-67$.

71. Amazon. [Online]. https://www.amazon.com/Amazon-Prime-Air/b? ie $=$ UTF8 \& node $=8037720011$

72. Frazzon, E. M., Silva, L. S., \& Hurtado, P. A. (2015). Synchronizing and improving supply chains through the application of cyberphysical systems. In IFAC, Florianópolis.

73. Zhang, N. (2018). Smart logistics path for cyber-physical systems with internet of things. Special section on collaboration for internet of things.

74. Strickland, E. (2017). Facebook announces "Typing-by-Brain" Project.

75. Pandarinath, C., Nuyujukian, P., Blabe, C. H., Sorice, B. L., Saab, J., Willett, F. R., Hochberg, L. R., Shenoy, K. V., \& Henderson, J. M. (2017). High performance communication by people with paralysis using an intracortical brain-computer interface. eLife. https://doi.org/ 10.7554/eLife. 18554

76. Neuralink. [Online]. https://neuralink.com/

77. Zhao, J., Lin, Y., Wu, J., Nyein, H. Y. Y., Bariya, M., Tai, L.-C., Chao, M., Ji, W., Zhang, G., Fan, Z., \& Javey, A. (2019). A fully integrated and self-powered smartwatch for continuous sweat glucose monitoring. ACS Sensors, 4, 1925-1933.

78. Jovanov, E. (2015). Preliminary analysis of the use of smartwatches for longitudinal health monitoring. In 201537 th annual international conference of the IEEE engineering in medicine and biology society $(E M B C)$, Milan.

79. Boletsis, C., McCallum, S., \& Landmark, B. F. (2015). The use of smartwatches for health monitoring in home-based dementia care. In Human aspects of IT for the aged population. design for everyday life (pp. 15-26).

80. Sun, X., Qiu, L., Wu, Y., Tang, Y., \& Cao, G. (2017). SleepMonitor: Monitoring respiratory rate and body position during sleep using smartwatch. In Proceedings of the ACM on interactive, mobile, wearable and ubiquitous technologies.

81. Nwosu, A. C., Quinn, C., Samuels, J., Mason, S., \& Payne, T. R. (2017). Wearable smartwatch technology to monitor symptoms in advanced illness. BMJ Supportive \& Palliative Care, 8, 237.

82. Mishra, T., Wang, M., Metwally, A. A., Bogu, G. K., Brooks, A. W., Bahmani, A., Alavi, A., Celli, A., Higgs, E., Dagan-Rosenfeld, O., Fay, B., Kirkpatrick, S., Kellogg, R., Gibson, M., Wang, T., \& Rolnik, B. (2020). Early detection of COVID-19 using a smartwatch.

83. Wang, X. V., \& Wang, L. (2018). Digital twin-based WEEE recycling, recovery and remanufacturing in the background of Industry 4.0. International Journal of Production Research, 57, 3892-3902.

84. Sharpe, R. G., Goodall, P. A., Neal, A. D., Conway, P. P., \& West, A. A. (2018). Cyber-physical systems in the re-use, refurbishment and recycling of used electrical and electronic equipment. Journal of Cleaner Production, 170, 351-361.

85. United Nations. Sustainable Development Goals. [Online]. https:// www.un.org/sustainabledevelopment/

86. Sassanelli, C., Rosa, P., Rocca, R., \& Terzi, S. (2019). Circular economy performance assessment methods: A systematic literature review. Journal of Cleaner Production, 229, 440-453.

87. Kristensena, H. S., \& Mosgaard, M. A. (2020). A review of micro level indicators for a circular economy-Moving away from the three dimensions of sustainability? Journal of Cleaner Production, 243,118531
88. Elia, V., Gnoni, M. G., \& Tornese, F. (2017). Measuring circular economy strategies through index methods: A critical analysis. Journal of Cleaner Production, 142, 2741-2751.

89. Vercalsteren, A., Christis, M., \& Hoof, V. V. (2017). Indicators for a circular economy. Summa Circular Economy Policy Research Centre.

90. European Commission. (2015). Circular Economy Package: Questions \& Answers. [Online]. https://ec.europa.eu/commission/press corner/detail/en/MEMO_15_6204. Accessed 29 Mar 2021.

91. Ellen MacArthur Foundation. (2017). Circulytics-Measuring circularity. [Online]. https://www.ellenmacarthurfoundation.org/resou rces/apply/circulytics-measuring-circularity. Accessed 4 Apr 2021.

92. Cradle to Cradle Products Innovation Institute. (2021). What is Cradle to Cradle Certified ${ }^{\circledR}$ ? Cradle to Cradle Products Innovation Institute. [Online]. https://www.c2ccertified.org/get-certified/produ ct-certification. Accessed 3 Apr 2021.

93. Chun-rong, J., \& Jun, Z. (2011). Evaluation of regional circular economy based on matter element analysis. Procedia Environmental Sciences, 11, 637-642.

94. IFIXIT. (2017). Smartphone Repairability Scores. [Online]. www. IFIXIT.com

Publisher's Note Springer Nature remains neutral with regard to jurisdictional claims in published maps and institutional affiliations.

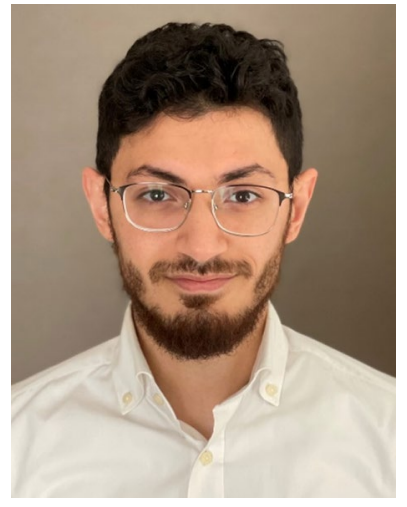

Aser Alaa Ahmed received a B.Sc. in mechanical engineering in 2019 from the American University of Sharjah (AUS), Sharjah, United Arab Emirates. He is currently pursuing a M.Sc. degree in mechanical engineering at AUS. His research focuses on sustainable manufacturing and applying circular economy concepts in engineering and in the automotive industry.

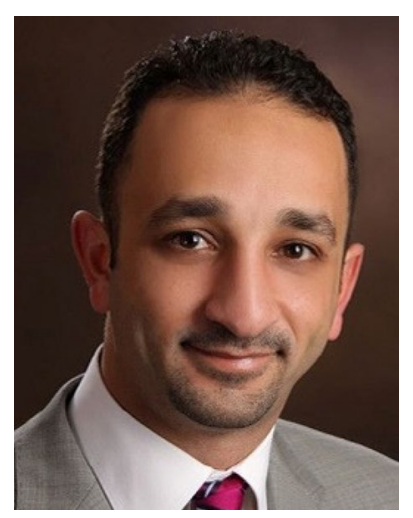

Mohammad A. Nazzal is an Associate Professor of Mechanical Engineering at the American University of Sharjah. His research focuses on modern manufacturing processes and sustainable manufacturing. He is a recipient of the IEEE Outstanding Branch Counselor award, GJU Outstanding Teaching award and several international awards. 


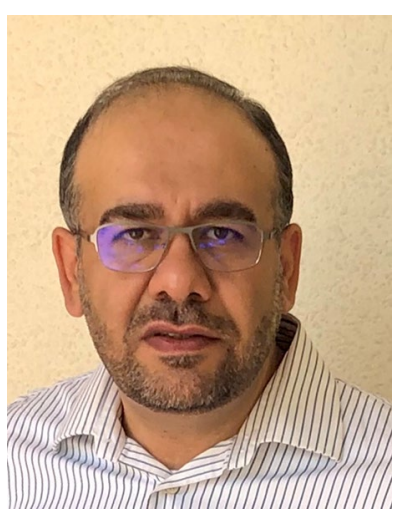

Basil M. Darras is an Associate Professor of Mechanical Engineering at the American University of Sharjah. His research focuses on advanced materials processing, friction stir welding/ processing and sustainable manufacturing. 